\title{
El problema genético del concepto de convencionalidad
}

\author{
The Genetic Problem of the \\ Conventionality Concept
}

O problema genético do conceito de convencionalidade

Eduardo Acosta Yparraguirre*

* https://orcid.org/0000-0001-5268-8327. Universidad Católica Santo Toribio de Mogrovejo, Perú. eacosta@usat.edu.pe

Recibido: 31/01/2019. Envío a pares: 19/03/2019 Aprobado por pares: 16/03/2020. Aceptado: 13/04/2020

DO.5294/dika.2020.29.1.5

Para citar este artículo / To reference this article / Para citar este artigo 


\section{Resumen}

Este artículo detalla el recorrido jurisprudencial en la formación del concepto de control de convencionalidad y describe su vocación expansionista, desde su aparición periférica hasta su presentación actual, que exige adecuaciones de la normatividad interna, procedimientos, actuación de jueces y funcionarios, entre otros requerimientos. Hecho este análisis, el estudio se dirige a estudiar el concepto oficial y el carácter vinculante que se le ha pretendido conferir. En este examen se dilucidará si alegar el principio de pacta sunt servanda internacional es suficiente o si el error exime la exigencia. Asimismo, se estudia la naturaleza jurídica de la jurisprudencia en el derecho internacional a fin de conocer cuál es su verdadera ubicación jerárquica y, por tanto, su fuerza obligatoria. Puestos en este punto, se realizará una investigación desde la filosofía del lenguaje para conocer si el propio enunciado y sus términos son acertados. Seguidamente, se enfrenta al control de convencionalidad con conceptos fundamentales del derecho como soberanía estatal y supremacía constitucional en el derecho interno, y principio de subsidiariedad de las vías internacionales en el derecho internacional. Finalmente, se expone la recepción de estos conceptos en el derecho peruano.

\section{Palabras clave}

Control de convencionalidad; control de constitucionalidad; soberanía; derechos humanos; supremacía constitucional; jurisprudencia vinculante. 


\section{Abstract}

This article details the jurisprudential path in the formation of the concept of Control of Conventionality and describes its expansionist vocation from its peripheral appearance to its current presentation that requires adjustments of internal regulations, procedures, judges and officials performances, among other requirements. Done this analysis, the study is aimed at analyzing the official concept and the binding nature that has been intended to confer, in this examination will be elucidated whether alleging the principle of international pacta sunt servanda is sufficient or if the error exempts the obligation. Likewise, the juridical nature of jurisprudence in International Law is studied in order to know what is its true hierarchical location and therefore its mandatory force. At this point an investigation will be made from the philosophy of language to know if the statement itself and its terms are correct. Next, this study confronts the Control of Conventionality with fundamental concepts of law such as state sovereignty and supremacy of the Constitution in domestic law and the principle of subsidiarity of international procedures in international law. Finally, the reception of these concepts in Peruvian law is exposed.

\section{Keywords}

Control of conventionality; control of constitutionality; sovereignty; human rights; supremacy of the Constitution; binding jurisprudence. 


\section{Resumo}

Este artigo detalha o caminho jurisprudencial na formação do conceito de "controle da convencionalidade" e descreve sua vocação expansionista desde seu surgimento periférico até sua apresentação atual, que requer ajustes de normas internas, procedimentos e desempenho de juízes e oficiais, entre outros requisitos. Feita essa análise, o estudo analisa o conceito oficial e o caráter vinculante que se pretendem conferir. Nesse exame será elucidado se a alegação de que o princípio da pacta internacional sunt servanda é suficiente ou se o erro isenta a obrigação. Da mesma forma, estuda-se a natureza jurídica da jurisprudência em Direito Internacional para saber qual é a sua verdadeira posição hierárquica e, portanto, sua força obrigatória. Nesse ponto, uma investigação é feita a partir da filosofia da linguagem para saber se a afirmação em si e seus termos estão corretos. Em seguida, este estudo confronta o controle da convencionalidade com conceitos fundamentais de Direito, como a soberania do Estado e a supremacia da Constituição no Direito interno, e o princípio da subsidiariedade dos procedimentos internacionais no Direito Internacional. Finalmente, é exposta a recepção desses conceitos no Direito peruano.

\section{Palavras-chave}

Controle de convencionalidade; controle de constitucionalidade; soberania; Direitos Humanos; supremacia da constituição; jurisprudência vinculante. 
Sumario: Introducción. 1. El germen de la idea. 2. El concepto y sus problemas genéticos. 2.1 El concepto oficial. 2.2 El pretendido carácter vinculante. 2.3 La naturaleza jurídica (y alcance) de la jurisprudencia en el derecho internacional. $2.4 \mathrm{Y}$, sin embargo, ¿qué diría la filosofía del lenguaje? 3. Soberanía del Estado y supremacía constitucional frente al control de convencionalidad. 4. Mientras tanto en el Perú. 5. Conclusiones. Referencias

\section{Introducción}

No creo en el control de convencionalidad. Al menos no en aquel concepto que se nos ofrece. El título del presente artículo hace referencia a la convencionalidad a secas y no menciona al control, y es adrede dado que, como explicaré en el desarrollo del presente trabajo, tal presunto control no se asume en su primera acepción de comprobación, que trae implícita la idea de evaluación, es decir, la posibilidad de examinar la conveniencia o el despropósito de interpretar o aplicar normas conforme a convenciones internacionales, no.

La convencionalidad se entiende como el control que debe ejercer el juez al cuidar la observancia y el arreglo que todos los actos y circunstancias deberían tener con respecto a los tratados, hecho que, por supuesto, termina incluyéndolo también a él mismo, dado que sus resoluciones y sentencias deben igualmente mantener tal adhesión. El concepto ya tiene una definición oficial que, como se expondrá, ha ido ensanchándose desde su origen.

La formación del concepto de control de convencionalidad ha sido un proceso modelado en la práctica, desde una idea incipiente encajada contingentemente dentro de otras, que toma cuerpo en cada sentencia, interpretando las normas y se reinterpreta a sí misma, hasta el definido protagonismo que revela en la actualidad. Sin embargo, a pesar de lo auspiciosa que puede parecer esta nueva institución, por enarbolar la protección internacional de los derechos humanos, vale la pena preguntarse si es conveniente. De esto se encarga el presente trabajo.

Entre las cosas que llaman la atención de este proceso de formación del concepto es que se ha tomado como modelo al control de constitucionalidad y, con base en sus particularidades, se ha ido edificando el control de convencionalidad; a partir de esto, cabe preguntarse si son equiparables o al menos asimilables entre sí. De otro lado, se encuentra la interrogante sobre el lenguaje para verificar si la fraseología utilizada es la correcta. De ambas cuestiones se encarga el presente estudio y aspira a demostrar, asimismo, que su tratamiento es deficiente y, por tanto, erróneo. El pretendido instituto nace fallido.

Su sola propuesta implica la conformidad de que un ente externo pueda obligar a un Estado a modificar su derecho; a ordenar que sus poderes constituidos procedan conforme a la interpretación de su tribunal; a adecuar sus normas, 
organismos autónomos, autoridades y funcionarios de acuerdo con sus disposiciones, en suma, que pueda relajar su soberanía. El propósito de este trabajo es exhibir este proceso de incursión y analizar las posibles consecuencias de la inserción del concepto convencionalidad en los sistemas jurídicos internos.

Es comprensible entonces que, conocido lo anterior, avancemos hasta las cuestiones sobre la soberanía del Estado y la supremacía de la Constitución y observemos cómo reaccionan al contacto con este nuevo concepto, dado que su debilitamiento se traduciría en una afectación vital para el Estado moderno, Estado constitucional de derecho, por definición. Esta intrusión en la actividad interna redelinea necesariamente al sistema jurídico y al cuerpo político, en este caso, exigiendo cumplimiento y adaptación de normas y actos, por esta razón es que aquello que se percibe al final no es un control de convencionalidad, sino una convencionalidad dirigida a controlar.

\section{El germen de la idea}

El origen $\mathrm{o}$, si se quiere, el indicio más antiguo, lo encontramos en el párrafo 27 del voto concurrente del magistrado Sergio García Ramírez en la sentencia del caso Myrna Mack vs. Guatemala, del 25 de noviembre de 2003. Hecha la interpretación en contrario de lo planteado por el jurista, queda claro que, en su opinión, todas las instituciones y los estamentos del Estado deben estar comprometidos, dado que una adhesión por partes en realidad no tendría ningún sentido, pues en suma no aseguraría nada. Solo una responsabilidad estatal total aseguraría el éxito de lo que él denomina "régimen convencional", en una fórmula ya bastante sugerente. Compromiso estatal obligatorio a todo nivel, ese es su deseo.

Tiempo después, el 7 de setiembre de 2004, el propio Sergio García Ramírez, en la sentencia del caso Tibi vs. Ecuador, ensayaría nuevamente el concepto, explicándolo mediante una analogía, de necesario análisis para comprobar su coherencia. Al estudiar el texto llama la atención el símil propuesto entre tribunales constitucionales y la Corte Interamericana de Derechos Humanos (Corte IDH), o entre constitución y convención, o entre Estado de derecho y orden internacional de la jurisdicción interamericana, como si estas instituciones tuvieran la misma naturaleza jurídica, pero de eso hablaremos más adelante, lo que se precisa a continuación en el voto es el núcleo de la figura jurídica que ya se veía evidenciado en la sentencia anterior. Se reafirma una situación comparativa entre una instancia más grande (interamericana) y una más pequeña (la estatal), afirmación con la cual se pretende fundamentar la falacia de hacer correspondencia entre "lo más extenso" y "lo mejor".

Recuérdese que la semántica y el uso de significados y significantes siempre han jugado un papel relevante en el derecho, de hecho, existen filosofías jurí- 
dicas consagradas al estudio de estos temas. Para concluir, ante la levedad del concepto "orden internacional", tan disperso como puede serlo, debe apartársele del conjunto que hemos denominado "instituciones" en este mismo párrafo, dado que por su porosidad y dispersión no le alcanza el fundamento para tal denominación.

Dos años después, el 26 de setiembre de 2006, en la sentencia del caso Caso Almonacid Arellano y otros vs. Chile, la Corte IDH, esta vez en una posición colegiada, precisó en su fundamento 124 lo que sería la real partida de nacimiento del control de convencionalidad. ${ }^{1}$ El concepto ha ido de la periferia al centro, ahora pertenece al propio texto de la sentencia elaborada como una voz conjunta del colegiado. El concepto es ahora una cuestión de la Corte $\mathrm{IDH}$, lo ha hecho suyo, lo acepta y lo promueve. Pues bien, en este párrafo se hace referencia de manera clara a las características que identifican al control de convencionalidad. La Corte IDH señala que, no obstante reconocer el imperio de la ley, la ratificación "obliga" a los jueces, por lo cual se encuentran "sometidos". Luego realiza la representación de un enfrentamiento entre leyes y convención, que da como resultado que las primeras siempre tendrán que adecuarse a la segunda, de lo contrario nacerán muertas. Hasta ahí todo se presenta más o menos congruente, pues, a despecho de los términos utilizados, es claro que los tratados son vinculantes. Lo que genera interrogantes es si las leyes nocivas perecen al contacto con la convención y sus cualidades, como si no hubiese otra instancia que no solo las pudiera contrarrestar, sino que su poder se presentara solemne, incuestionable, majestuoso y que ya existiera con éxito sostenido en el tiempo y corroborado por la actividad de juristas, jueces y otros operadores del derecho: me refiero como es obvio a la constitución.

De otro lado, se expresa un deber sobre el poder judicial, con lo cual habría que preguntarse si es posible ejercer una legítima obligación sobre un poder autónomo del Estado, especialmente si se trata de un agente externo a su propio Estado. Sin embargo, ello no queda ahí, pues tal exigencia se extiende a la obligación de controlar no solo lo que la Convención Americana sobre Derechos Humanos (CADH) precisa como positividad, sino también acatar sin cuestionamiento lo que la Corte IDH indica, dado que esta es el supremo intérprete de la $\mathrm{CADH}$ y, al fin y al cabo, terminará estableciendo lo que en la norma escrita se quiere decir.

Cerca de un par de meses después, el 24 de noviembre de 2006, la Corte IDH dictó sentencia en el Caso Trabajadores cesados del Congreso (Aguado Alfaro

1 "El control de convencionalidad, con dicha denominación, aparece por primera vez en la jurisprudencia contenciosa de la Corte IDH en el caso Almonacid Arellano vs. Chile. Con anterioridad, el juez Sergio García Ramírez, en sus votos de los casos Myrna Mack y Tibi, había realizado una aproximación conceptual al control de convencionalidad que se realiza en la sede interamericana y en el ámbito interno de los Estados, pero en Almonacid Arellano la Corte precisa sus principales elementos" (Cuadernillo de Jurisprudencia de la Corte Interamericana de Derechos Humanos núm. 7: Control de Convencionalidad, p. 4). 
y otros vs. Perú) esgrimiendo en su fundamento 128 argumentos similares a los expuestos en la sentencia Almonacid ya citada; de hecho, en el mismo texto se hace referencia a ella, en la cita 77 que se remite a confrontar.

Es importante tomar en consideración un apunte advertido por Ariel E. Dulitzky ${ }^{2}$ acerca de la explícita intención extensiva del concepto, que puede pasar desapercibido por tratarse nuevamente de semántica, aunque va acompañado en seguida de un fundamento jurídico, ambos sumados dicen mucho de la tendencia que ha ido procesando la Corte IDH. Lo que el autor trata de resaltar son dos extremos, como hemos visto: primero que, mientras en el caso Almonacid se habla de "una especie de 'control de convencionalidad"', en el caso Aguado se deja atrás esta incierta expresión para pasar a los términos más contundentes de un "control de convencionalidad" puro y simple al cual, obviamente, se atribuye el "deber" judicial ya mencionado en la sentencia Almonacid. No es "una especie de", es el control de convencionalidad.

Segundo, destaca la extensión del concepto que desea darle la Corte IDH, dado que ahora aclara lo que se intuía: que esta fortificada figura jurídica debe ser recurrida de parte, pero también, y principalmente, de oficio, es decir, que el juez debe actuar por su propio criterio con respecto al control de convencionalidad, pero ese criterio debe ser obedecerlo y aplicarlo. Esto, como vemos, se produjo en una sentencia emitida en un lapso de no más de dos meses con respecto a la anterior en el caso Almonacid, es posible que con la motivación de complementar rápidamente el concepto.

Tiempo después, el 12 de agosto de 2008, el concepto aparece nuevamente. Sucede en los fundamentos 179 y 180 de la sentencia del Caso Heliodoro Portugal vs. Panamá. De aquí se desprenden tres cosas: una acción negativa

2 Ariel Dulitzky, "An Inter-American Constitutional Court? The Invention of the Conventionality Control by the Inter-American Court of Human Rights", en Texas International Law Journal 50 (1) (2015), pp. 45-93. “While the need for the compatibility of domestic legislation with the Convention is nothing new in the Court's jurisprudence, Almonacid, for the first time, introduced the requirement that national judges exercise this compatibility control between the domestic norms and the Convention. In Dismissed Congressional Employees v. Peru, the Court specified that the conventionality control (no longer referring to it as 'a sort of ') must be exercised ex officio or sua sponte by all judicial authorities. Additionally, the Court clarified that judges must exercise the control within 'the context of their respective spheres of competence and the corresponding procedural regulations.' It added that ' $[\mathrm{t}]$ his function should not be limited exclusively to the statements or actions of the plaintiffs in each specific case, although neither does it imply that this control must always be exercised, without considering other procedural and substantive criteria regarding the admissibility and legitimacy of these types of action'."

"Si bien la necesidad de compatibilidad entre la legislación interna y la Convención no es nueva en la jurisprudencia de la Corte, el caso Almonacid introdujo por primera vez el requisito de que los jueces nacionales ejerzan este control de compatibilidad entre las normas internas y la Convención. En el caso Trabajadores cesados del Congreso vs. Perú, la Corte especificó que el control de convencionalidad (al cual no se refiere más como 'una especie de'), debe ser ejercido ex officio o sua sponte por todas las autoridades judiciales. Adicionalmente, la Corte aclaró que los jueces deben ejercer el control dentro del 'marco de sus respectivas competencias y de las regulaciones procesales correspondientes'. Agregó que '[E]sta función no debe quedar limitada exclusivamente por las manifestaciones o actos de los accionantes en cada caso concreto, aunque tampoco implica que ese control deba ejercerse siempre, sin considerar otros presupuestos formales y materiales de admisibilidad y procedencia de ese tipo de acciones"' (traducción propia). 
(supresión), una acción positiva (expedición) y una extensión con respecto al control de convencionalidad, tres elementos que introducen un nuevo enfoque en el estudio del concepto y sus obligaciones. Lo que ahora interpreta la Corte IDH en este orden de ideas es una promoción activa, que se enclava en el mismo derecho interno. Se le exige a los Estados que, en virtud de su adhesión al Convenio, como afirma que es menester en todo tema de tratados, deben adecuar su norma interna, de manera que resulte posible la realización del instrumento internacional.

Esta modificación implica "supresión" y "expedición" de normas, lo cual deja flotando la pregunta, nuevamente, sobre si es lógica y legítimamente posible que un ente externo pueda obligar a un Estado soberano ${ }^{3}$ a hacer o deshacer su derecho, todo ello mediante sus poderes constituidos y sus organismos autónomos.

La tercera novedad es la extensión de la aplicación del concepto. La Corte IDH ha decidido ensanchar sus fronteras y ahora no solo habla de "jueces", sino también de "operadores de justicia". Vamos a interpretar estos enunciados a la luz de las siguientes jurisprudencias.

Primero, revisaremos lo expuesto el 23 de noviembre de 2009 en la sentencia del Caso Radilla Pacheco vs. México, fundamentos 338 y 339. El foro es sumamente directo y ha decidido extender el terreno. Ahora son dos tópicos los elegidos y los refiere con claridad meridiana: primero, ya no es suficiente con asegurar la "supresión o expedición de normas" a fin de adecuar el derecho interno a lo establecido por la Convención, sino que alude también a la necesidad de poner en marcha "prácticas estatales" con el mismo objetivo. En suma, lo que propugna es un cambio en el campo de las normas y en el campo de los hechos; teoría y práctica; concepto y realidad; validez y eficacia. Líneas más adelante reafirma el deber de los jueces con respecto al control de convencionalidad -lo cual no es nuevo- y repite que esta actividad debe desarrollarse de oficio.

Segundo, se trata de expandir el área de obligación: no es suficiente con aplicar la $\mathrm{CADH}$, sino que es igualmente obligatorio mantener observancia plena de la interpretación que sobre ella realiza la Corte IDH. En suma, se le exigen al Estado obligaciones en términos legislativos y judiciales. Obligaciones legislativas: que se adecue al tratado, incluso si deben crearse o derogarse normas. Obligaciones judiciales: sus jueces deben aplicar, no solo la positividad

3 Alberto Borea Odría, Los elementos del Estado moderno, Lima, Centro de Estudios Legislativos, Económicos y Sociales, 1994, p. 396. El autor cita la definición de Soberanía de Georg Jellinek, la cual por acertada servirá como referencia en el transcurso del presente trabajo: “la evolución histórica de la soberanía nos demuestra que esta significó la negación de toda subordinación o limitación del Estado a cualquier otro poder. Poder soberano de un Estado es, por tanto, aquel que no reconoce ningún otro superior a sí; es, por consiguiente, el poder supremo e independiente". 
del tratado, sino también su interpretación. Como vemos, la inserción de la CADH es transversal y a todo nivel. Vertical, visto el derecho como imposición normativa estatal, y horizontal, visto el derecho como práctica judicial. Esto lo desarrollaremos en las siguientes sentencias.

En primer lugar, si viramos hacia la sentencia del caso Fernández Ortega y otros vs. México, del 30 de agosto de 2010, constataremos que el tenor, salvo modificaciones mínimas más formales que de fondo, se repite. En este extremo, la Corte IDH decide adjuntar a su novedoso concepto el numeral normativo que lo sustentaría, el artículo 2 de la CADH, y este nos remite al artículo 1, ${ }^{4}$ de ello podemos advertir una posición positiva y otra negativa en la norma, es decir, a asegurar derechos y libertades, por una parte, y, por otra, a una enumeración de circunstancias sobre las que se desea enclavar el principio de no discriminación. Todo ello está muy bien, pero cabe nuevamente la pregunta sobre si existe ya un elemento preceptivo de fuerza vinculante y máxima jerarquía, que obligue sin cuestionamientos, que sea cercano e inmediato -normativamente hablando- y que, fundamentalmente, domine y de la misma manera pertenezca al propio ordenamiento normativo donde los hechos ocurren. La respuesta es sí; y, una vez más, se trata de la constitución.

No podemos perder de vista la acotación que la sentencia hace acerca de la interpretación de la Constitución mexicana. Esto se repite en la sentencia del 31 de agosto de 2010, en el caso Rosendo Cantú y otra vs. México, fundamentos 218 y 219.

Como vemos, en las sentencias Fernández Ortega y Rosendo Cantú (ambas distanciadas solo por un día), la Convención afirma que la interpretación del artículo 13 de la Constitución mexicana "debe ser coherente con los principios convencionales y constitucionales de debido proceso y acceso a la justicia". Esto es lógico si hablamos de la Constitución, esta prevé dichos principios y son sin duda, de observancia obligatoria, no solo en México, sino en casi todos los países de Occidente justamente a partir de sus propias constituciones, por ello cada Estado y sus jueces deberán tenerlos en cuenta en toda actividad pública. Esto ya está más que entendido, no hay duda sobre ello, y todo comentario posterior no hará sino abonar positivamente en la comprensión del tema. Sin embargo, cabe aquí la pregunta: ¿puede la CADH dirigirse a un Estado y pres-

CADH, “artículo 1. Obligación de Respetar los Derechos 1. Los Estados parte en esta Convención se comprometen a respetar los derechos y libertades reconocidos en ella y a garantizar su libre y pleno ejercicio a toda persona que esté sujeta a su jurisdicción, sin discriminación alguna por motivos de raza, color, sexo, idioma, religión, opiniones políticas o de cualquier otra índole, origen nacional o social, posición económica, nacimiento o cualquier otra condición social. 2. Para los efectos de esta Convención, persona es todo ser humano. Artículo 2. Deber de Adoptar Disposiciones de Derecho Interno si en el ejercicio de los derechos y libertades mencionados en el artículo 1 no estuviere ya garantizado por disposiciones legislativas o de otro carácter, los Estados parte se comprometen a adoptar, con arreglo a sus procedimientos constitucionales y a las disposiciones de esta Convención, las medidas legislativas o de otro carácter que fueren necesarias para hacer efectivos tales derechos y libertades". 
cribirle que tiene el "deber" de interpretar un artículo de su propia Constitución, que es la norma de normas de su ordenamiento jurídico, de acuerdo con el texto de la Convención? ¿Tiene realmente capacidad para ello? Y, de otro lado, en términos prácticos, ya que como vimos, la propia Constitución y sus intérpretes han dilucidado el tema y nadie duda de la obligatoriedad de estos principios, resulta pertinente la pregunta acerca de las prescripciones de la Corte IDH en su jurisprudencia: ¿son oficiosas?

Decíamos líneas arriba que el camino del concepto ha sido el de un progresivo ensanchamiento de fronteras, como lo podemos notar en las sentencias citadas aquí. Pues bien, el 26 de noviembre de 2010 la Corte IDH decidió continuar en este proceso y ha llevado al control de convencionalidad a un nuevo nivel. Se trata del fundamento 225 de la sentencia del caso Cabrera García y Montiel Flores vs. México.

Vemos aquí otra novedad de la Corte IDH, pues ha extendido el deber de observancia de la Convención y la interpretación oficial de la misma y su consiguiente obligación a proceder de oficio, sin necesidad de una petición -característica que ya había sido referida en sentencias anteriores-, no solo a los jueces, sino también a los demás "órganos vinculados a la administración de justicia en todos los niveles".

¿De qué hablamos?: Ministerio Público, Defensoría del Pueblo, Tribunal Constitucional, sistema administrativo, Ministerio de Justicia, y me atrevería a decir que esta primera intención abarcaría también a órganos indirectamente relacionados con el sistema judicial, como aquellos entes encargados de nombrar y ratificar a jueces y fiscales (Junta Nacional de Justicia en el Perú), los ministerios dedicados a minorías o poblaciones en situación de desventaja social (Ministerio de la Mujer y Poblaciones Vulnerables en el Perú) y el Sistema Electoral (en el Perú, como en otras partes del mundo, el sistema electoral posee un tribunal, en este caso denominado Jurado Nacional de Elecciones). Todos ellos cumplen de una u otra manera con aquel requerimiento de ser "órganos vinculados a la administración de justicia en todos los niveles".

El 24 de febrero de 2012, en la sentencia del caso Atala Riffo y niñas vs. Chile, fundamentos 282, 283 y 284, a casi ya diez años del párrafo 27 del voto concurrente del juez Sergio García Ramírez en la sentencia del 25 de noviembre de 2003 sobre el caso Myrna Mack vs. Guatemala, la Corte IDH siente que ya está en posición de hacer una veloz enumeración a manera de recuento y ejemplo acerca de la aceptación que el control de convencionalidad ha tenido en el mundo jurídico, con especial énfasis en aquellos "tribunales de la más alta jerarquía en la región".

La otra particularidad marcada en esta sentencia señala que "con base en el 175 control de convencionalidad, es necesario que las interpretaciones judiciales 
y administrativas y las garantías judiciales se apliquen adecuándose a los principios establecidos en la jurisprudencia de este Tribunal en el presente caso". Es decir, explícitamente se agrega a las decisiones judiciales también las administrativas $\mathrm{y}$, por tanto, estas deberán formularse de acuerdo con el control de convencionalidad. En suma, lo comentado a manera de intuición en la anterior sentencia se materializa en esta.

Finalmente (aunque no por falta de ejemplos, sino porque con lo descrito ha quedado claro el punto), cabe apuntar lo expuesto el 24 de febrero de 2011, en el fundamento 239 de la sentencia del Caso Gelman vs. Uruguay, el cual se constituye como un texto poderoso y ambicioso. Puede notarse en su redacción la radical diferencia existente entre este y las aún modestas precisiones elaboradas en las primeras sentencias. Aquí se escucha sin dudas una declaración de intenciones y se procede a un nuevo alargamiento de las fronteras del concepto. La sentencia afirma que un régimen democrático no asegura en sí mismo la observancia del derecho internacional de los derechos humanos (DIDH), al cual por un ejercicio inferencial desconocido atribuye la capacidad de demostrar cuándo estamos realmente frente a una democracia ("La legitimación democrática de determinados hechos o actos en una sociedad está limitada por las normas y obligaciones internacionales de protección de los derechos humanos reconocidos en tratados como la Convención Americana"). Concuerda todo el mundo jurídico, que un régimen democrático verdadero se muestra de igual modo, tanto en el plano formal como en el sustancial, lo que no queda claro es la relación directa que aduce la Corte IDH entre la protección internacional y estos presupuestos. No se advierte una evidente relación causa-efecto, en tanto que la Constitución y el bloque de constitucionalidad, mediante derecho interno, ya han resuelto el tema.

De otro lado, llama la atención esta vez el directo pronunciamiento sobre aquellos que tienen el deber de observar el control de convencionalidad; al respecto, la Corte IDH afirma que "es función y tarea de cualquier autoridad pública y no solo del Poder Judicial". Con esto queda claro que esta responsabilidad es del Estado en todas sus instancias y no únicamente una tarea jurisdiccional.

\section{El concepto y sus problemas genéticos}

\subsection{El concepto oficial}

Sobre el control de convencionalidad existen diversas concepciones, todas con un común denominador, aquel que toma prestada la idea del control de constitucionalidad, es decir, si en este último caso se afirma que todo acto de poder debe mantener plena observancia, adherencia y acatamiento de la constitución, por un ejercicio analógico se señala que al ubicarse los tratados sobre 
derechos humanos al mismo nivel jerárquico que la primera norma nacional, les correspondería similar atribución y deferencia. Esta aseveración concluye invocando el principio pacta sunt servanda, en pos de un argumento de cierre que termine por completar la idea de una forma contundente: los tratados deben cumplirse.

Si debemos rastrear un concepto de "fuente autorizada" es inevitable recurrir a lo planteado por la Corte IDH. No sucede a menudo que conceptos jurídicos sean creados o definidos por sedes judiciales, sin embargo, como hemos visto, el denominado control de convencionalidad ha sido y está siendo desarrollado por el foro internacional más grande del continente americano, o por lo menos el que más naciones congrega, por ello, acudir a su posición sobre este particular es, en suma, un ejercicio de "interpretación auténtica".

Según el Cuadernillo núm. 7 de Jurisprudencia de la Corte IDH:

En la jurisprudencia de la Corte Interamericana (Corte IDH), ha surgido el concepto control de convencionalidad para denominar a la herramienta que permite a los Estados concretar la obligación de garantía de los derechos humanos en el ámbito interno, a través de la verificación de la conformidad de las normas y prácticas nacionales, con la Convención Americana [sobre] Derechos Humanos (CADH) y su jurisprudencia. $^{5}$

De lo precisado por la Corte IDH podemos extraer algunas conclusiones. La primera es obvia, la figura del control de convencionalidad es un producto judicial surgido a partir del ejercicio en el tribunal, no es un concepto jurídico que se aplica luego en litis, sino que de la litis se ha desprendido un concepto. Esto, por supuesto, no califica a la figura, solo describe su origen. Como herramienta es un instrumento que, obviamente, se ha insertado en el mundo doctrinario, del cual no provino, pero que ha devenido en materia abundante para la argumentación. Sin embargo, como herramienta es principalmente un medio y como tal no es un fin en sí mismo, sino que asume un objetivo, el cual en el propio texto citado se revela en dos expresiones: "obligación de garantía" y "verificación de conformidad".

La primera de ellas, "obligación de garantía", refiere una sujeción de la normatividad interna de cada país, de modo que se asegure el respeto y la promoción permanentes de los derechos humanos. Llegado a este punto, no hay duda de que esta propensión y deseo de la Corte IDH resultan encomiables, nadie sostendría lo contrario; sin embargo, valgan verdades, no se advierte qué tan necesario resultaría un pronunciamiento de este tipo si tenemos en cuenta que todas las Constituciones de este lado del mundo ya lo prescriben con la fuerza vinculante que implica ser la norma fundamental de cada nación.

5 Cuadernillo de Jurisprudencia de la Corte Interamericana de Derechos Humanos núm. 7: Control de Convencionalidad, p. 2. 
La segunda expresión, "verificación de conformidad", trae implícito un concepto de subordinación, no se trata de otra cosa que de una adecuación mandatoria. Una verificación es una revisión, la constatación de algo con respecto a una idea o un patrón predeterminado, en este caso es el ajuste de las "normas y prácticas nacionales" de acuerdo con la CADH y su jurisprudencia; ya vemos que este carácter vinculante se extiende no solo a la norma positiva, sino también al producto judicial. Semántica y gramática son claras, son las normas y prácticas internas las que deben entrar en concordancia con el tratado y no al revés, tampoco hay un plano de igualdad u horizontalidad, esto entraña, evidentemente, un desnivel de jerarquías y una situación de sumisión $\mathrm{y}$ acatamiento de una con otra.

El destacado tratadista Miguel Carbonell señala con respecto al control de convencionalidad que este

... debe entenderse como una herramienta que permite a los jueces contrastar las normas generales internas frente a las normas del sistema convencional internacional (tratados internacionales, pero también derecho derivado de los mismos). Esto significa que los jueces nacionales deberán desarrollar -de oficio- una serie de razonamientos que permitan la aplicación más amplia posible y el mayor respeto a las obligaciones establecidas por los tratados internacionales. Lo anterior puede conducir, en un caso extremo, a que un juez inaplique una norma interna cuando esté en contradicción con una norma internacional. ${ }^{6}$

Si tenemos en cuenta lo reseñado en este trabajo sobre la evolución que la proposición ha tenido a través de la jurisprudencia de la Corte IDH, podemos extraer las ideas principales a fin de ensayar un concepto. Podríamos decir, tentando una definición, que el control de convencionalidad es el deber de observancia obligatoria que tienen los jueces y toda autoridad pública con respecto al texto normativo de la CADH y la jurisprudencia de la Corte IDH, que es su máximo intérprete. Esta actividad implica de parte de todo el aparato del Estado, tanto la expedición de normas y desarrollo de prácticas que conduzcan a promover y mantener las garantías previstas en la Convención, así como la supresión, también de normas o prácticas que impliquen violación de dichas garantías.

\subsection{El pretendido carácter vinculante}

Vamos a revisar otra referencia conceptual, esta vez invocando el carácter vinculante de los acuerdos internacionales: el ya mencionado pacta sunt servanda. Susana Mosquera, como otros autores que hacen referencia explícita o implícita a dicho precepto, indica que:

6 Miguel Carbonell, “Introducción general al control de convencionalidad”, en Luis González y Diego Valadés (coords.), El constitucionalismo contemporáneo, México D.F., Fondo Editorial de la Universidad Nacional Autónoma de México, 2013, p. 71. 
Ni bueno ni malo, el control de convencionalidad es lo que tiene que ser, una consecuencia lógica de la obligación que asume el estado miembro cuando suscribe una obligación internacional. Aceptar su naturaleza jurídica y no política puede ser útil para que los operadores jurídicos nacionales le tomen cariño a esta herramienta y comiencen a utilizarla para fortalecer la aplicación del tratado en sede nacional. Para conocerla mejor deviene en esencial tener presente que se trata de una herramienta de derecho internacional que presenta los rasgos comunes de todo tratado y las características particulares del contexto regional en que es aplicada.?

Hay varios términos y conceptos que resulta necesario revisar en esta proposición. Lo primero: ¿el control de convencionalidad puede no ser "ni bueno, ni malo"? No, como todo acto humano está sujeto a un juicio de valoración. El hecho de considerarlo como una consecuencia lógica de la obligación internacional radica en la suscripción del tratado y en el espíritu del mismo, lo cual, en primer lugar, como veíamos líneas arriba, no sería necesario si ya está previsto en las normas internas, se condice con la Constitución nacional o esta, con toda la fuerza normativa, autónoma, soberana e incondicionada ya protege el derecho en cuestión y, segundo, habría que considerar si la interpretación que hace la Corte IDH sobre la CADH respeta el espíritu de la misma y, asimismo, no vulnera los principios de la nación que están previstos en la constitución, o si es legítimo restringir el razonamiento de los jueces (representantes de un poder del Estado, nada menos) u otros operadores del derecho. Es demasiado sencillo pasar a la obligación internacional y afirmar que esta debe cumplirse. Dejar de razonar o marcar el campo de acción a los encargados de impartir justicia recorta sus facultades en la práctica y la esencial capacidad que deberían tener intacta, basada en la independencia de los poderes y su libertad tanto individual como institucional: la capacidad de disentir.

De hecho, esta capacidad ha sido el fundamento que por siglos ha permitido al hombre enfrentarse a la ley escrita y, por ello, si hablamos de principios, este hace referencia a uno más antiguo y dotado de un poder iusfilosófico definitivamente más fuerte, del cual tenemos conocimiento desde los inmemoriales tiempos de Antígona en Sófocles y Santo Tomás de Aquino, ${ }^{8}$ hasta el aporte

$7 \quad$ Susana Mosquera Monelos, “Reflexiones sobre la interpretación de la convencionalidad de los derechos humanos en un caso de justicia transicional", en Pedro Grández Castro (coord.), Cuadernos sobre jurisprudencia constitucional, núm. 11, Lima, Palestra editores, 2016, pp. 49-79.

8 "Si una ley es injusta porque contradice su fin: el ser un ordenamiento hacia el bien común (así sucedería con una ley que impone un impuesto innecesario), o si lo es por transgredir la potestad del legislador, o lo es por su forma (al repartir cargos, así sea en favor del bien común, de manera no proporcional), dicha ley sería más que injusta violenta. Por lo tanto, no obligará en el foro de la conciencia, 'a no ser para evitar algún escándalo o desorden, en favor de lo cual el hombre debe también saber ceder su derecho' (I, II, q. 96, art. 4). Pero además podemos hablar de una ley humana como injusta en otro sentido: porque se contrapone a la ley divina, 'como las leyes de los tiranos que imponen la idolatría o cualquier otro acto contra la ley de Dios'. No estamos obligados a seguir estas leyes en ningún caso" (David Sobrevilla, Historia de la filosofía del derecho, Lima, Editorial Universitaria de la Universidad Ricardo Palma, 2012, tomo I, p. 131). Por su parte, Welzel señala: "Solo en tanto que la ley positiva es deducida de una de estas maneras de la ley natural, tiene fuerza de ley, ratio legis y obliga en conciencia a los súbditos. Una ley, en cambio, que se aparta del derecho natural no es verdadera ley, lex legalis, sino solo una corrupción de su propio sentido, una legis corruptio. Esta última no obliga en conciencia, aunque, sin embargo, puede ser obedecida, para evitar escándalo y perturbación. 
fundamental de Gustav Radbruch ${ }^{9}$ con su célebre fórmula, y otros posteriores, contribuciones que en la lucha entre el iunsturalismo y el iuspositivismo de una u otra manera han propuesto este precepto de validez evidente: nadie está obligado a cumplir un derecho injusto. Otras formulaciones también se han propuesto, como que el derecho injusto no es derecho o que el derecho injusto es falso derecho. Todas ellas afirman lo mismo.

Esto, como es obvio, lo señalo en referencia justamente a la posible desnaturalización del espíritu de la CADH que mencionaba antes, o simplemente a los potenciales errores en los cuales los jueces de la Corte IDH podrían recaer, la pregunta cae de madura: ¿los Estados están obligados a cumplir errores? Claro está, esta pregunta no es retórica, pues para hacer fundamento sobre aquello que podría representarse como la piedra de toque que reconocería estos errores tenemos sustentos tanto teóricos como prácticos de una intensidad jurídica indubitable: la constitución formal y material, el bloque de constitucionalidad y los principios que los sustentan.

\subsection{La naturaleza jurídica (y alcance) de la jurisprudencia en el derecho internacional}

Si leemos el punto anterior, podría erróneamente concluirse que hemos cometido un desliz en dirección al objetivo, atribuyendo a la jurisprudencia las calidades de la norma escrita. Bien, ni es un error al advertir las definiciones, ni se ha confundido o forzado la traslación de un concepto en otro, por el contrario, el deslinde de estas posibles interpretaciones se materializa mediante fundamentos cuya notable evidencia aclara estas proposiciones.

Mireya Castañeda destaca con acierto la ascendencia del Estatuto de la Corte Internacional de Justicia (CIJ) en el derecho internacional público y la apreciación que se tiene de la jurisprudencia en este texto normativo (arts. 38 y 59), ${ }^{10}$

Solo en el caso de que vulnere la misma lex divina, está prohibido obedecerla en absoluto" (Hans Welzel, Introducción a la filosofía del derecho, 2 ed., Madrid, Aguilar, 1979, p. 57).

9 "Por donde vemos cómo, a la vuelta de un siglo de positivismo jurídico, resucita aquella idea de un derecho superior a la ley, supralegal, aquel rasero en el que medir las mismas leyes positivas y considerarlas como actos contrarios a Derecho, como desafueros bajo forma legal. Hasta qué punto deba atenderse a la justicia cuando esta exija la nulidad de las normas jurídicas contrarias a ella y en qué medida debe darse preferencia al postulado de la seguridad jurídica, si esta impone la validez y el reconocimiento del Derecho estatuido, aun a trueque de su injusticia, son problemas que hemos examinado y procurado ya resolver en páginas anteriores. El camino para llegar a la solución de estos problemas va ya implícito en el nombre que la Filosofía del Derecho ostentaba en las antiguas Universidades y que, tras muchos años de desuso, vuelve a resurgir hoy: en nombre y en el concepto de Derecho natural" (Gustav Radbruch, Introducción a la filosofía del derecho, México D.F., Fondo de Cultura Económica, 2005, p. 180).

10 "[S]e precisó que el Derecho Internacional de los Derechos Humanos es una rama del Derecho Internacional Público; por ello, en las próximas líneas se parte del estudio tradicional de las fuentes indicadas en el Estatuto de la Corte Internacional de Justicia (ECIJ), pero con especial atención en la aplicación y en los elementos característicos y distintivos que han surgido en materia de derechos humanos. [...] El Estatuto de la Corte Internacional de Justicia, que ha servido como referencia típica, indica sobre las fuentes del Derecho Internacional Público: Artículo 38 1. La Corte, cuya función es decidir conforme al derecho internacional las controversias que le sean sometidas, deberá aplicar: a. las convenciones internacionales, sean generales o particulares, que 
de ello podemos colegir algunas consecuencias importantes. El numeral $38 \mathrm{del}$ Estatuto de la CIJ, a pesar de los años, sigue siendo un referente de recurrente observancia y esto a causa de tres motivos: primero, el vínculo evidente que genera para un Estado miembro de la Organización de las Naciones Unidas (ONU); segundo, proporciona un orden dentro de la normatividad jurídica internacional incierta y aún no unificada globalmente (no podemos hablar de un ordenamiento jurídico per se, por el contrario, aún estamos frente a un desorden jurídico; de entrada no podemos afirmar que esto configure una desventaja, el análisis de esta coyuntura corresponderá a otro estudio), y tercero, es la única referencia de este tipo existente en el campo del derecho internacional, por tanto, pueden haber discrepancias al respecto, pero en definitiva se trata de una remisión obligatoria. Esta ha sido y continúa siendo la tendencia en la doctrina y así se plantea en textos especializados. ${ }^{11}$

Ahora bien, con respecto al orden jerárquico que parece proponerse en la enumeración de los incisos del artículo en cuestión, aún existe discrepancia doctrinal; esto no quita, sin embargo, que se lo tome como referencia especialísima, fundamentalmente por el carácter explicativo que posee y por la secuencia lógica que muestra en los supuestos, proponiendo una gradación de mayor a menor importancia y orden en la recurrencia. ${ }^{12}$

establecen reglas expresamente reconocidas por los estados litigantes; b. la costumbre internacional como prueba de una práctica generalmente aceptada como derecho; c. los principios generales de derecho reconocido por las naciones civilizadas; $d$. las decisiones judiciales y las doctrinas de los publicistas de mayor competencia de las distintas naciones, como medio auxiliar para la determinación de las reglas de derecho, sin perjuicio de lo dispuesto en el artículo 59. Artículo 59. La decisión de la Corte no es obligatoria sino para las partes en litigio y respecto del caso que ha sido decidido. Los artículos citados son expresados en función de la Corte Internacional de Justicia, sin embargo, particularmente el artículo 38 es considerado como referente respecto de las fuentes del derecho internacional" (Mireya Castañeda, El derecho internacional de los derechos humanos y su recepción nacional, México D.F., Comisión Nacional de los Derechos Humanos, 2012, p. 32).

11 "Al ser aceptado el artículo 38 por la totalidad de los miembros de la Organización de las Naciones Unidas, ya que todos ellos son ipso facto partes en el Estatuto, se puede decir que esta disposición representa la enunciación más autorizada de las llamadas fuentes formales del derecho internacional público" (Ricardo Méndez Silva y Alonso Gómez Robledo, Derecho Internacional Público, México D.F., Universidad Nacional Autónoma de México, 1981, p. 11). Véase también Mónica Martínez y Jorge Peláez (coords.), Curso básico de derecho internacional, México D.F., Comisión de Derechos Humanos del Distrito Federal, 2012, Módulo III, p. 36. Debido a la inexistencia de otra referencia normativa de mayor peso, el punto necesario de partida para hablar de las fuentes del derecho internacional es el artículo 38 del Estatuto de la Corte Internacional de Justicia (CIJ), aun cuando sea insuficiente y anacrónico. Su origen obedece a la reglamentación de la manera en que debían solucionarse las controversias que fueran sometidas a la Corte Permanente de Justicia Internacional. En 1945, el contenido de dicha disposición fue reproducido por la entonces nueva CIJ. A partir del análisis de dicho artículo parece que los tratados internacionales, la costumbre internacional y los principios generales del derecho (aun cuando en estos últimos se conserve la mención de "reconocidos en las naciones civilizadas") constituyen fuentes torales, mientras que las decisiones judiciales y la doctrina son fuentes auxiliares en la medida en que ayudan a determinar el contenido de las normas principales.

12 En esta misma línea se pronuncia Matthias Herdegen, al indicar lo siguiente: “Las disposiciones del artículo 38 número 1 del Estatuto de la Corte Internacional lista en los incisos a-c fuentes propias del derecho internacional y en el inciso d las fuentes interpretativas del derecho (instrumentos de apoyo para la interpretación del derecho internacional). La secuencia de las fuentes del derecho internacional en el artículo 38, número 1, incisos a-c del Estatuto de la Corte Internacional corresponde al orden en el cual se aplican regularmente los principios del derecho internacional a un asunto. De este modo, quien aplique el derecho (por ejemplo, un tribunal nacional o internacional) acudirá en primer lugar por lo general, a los tratados vigentes entre las partes, luego a las reglas del derecho internacional consuetudinario y finalmente, a los principios generales del derecho internacional. Esto, sin embargo, no tiene implicaciones todavía sobre el orden jerárquico de las fuentes del derecho internacional. Por tanto, los Estados y los demás sujetos del derecho internacional pueden, mediante acuerdos, separarse del derecho internacional consuetudinario solo bajo reserva del derecho 
La siguiente interrogante que aparece de manera natural es aquella que se cuestiona sobre el carácter de las fuentes y, en nuestro caso, específicamente sobre la jurisprudencia, dado que es el área donde se desenvuelve la presente investigación. La primera respuesta para esta cuestión sobreviene de una apreciación literal del inciso d, de allí se pueden extraer dos enunciados reveladores: "medio auxiliar" y, respecto del artículo 59, citado, "obligatorio solo para las partes en litigio". Este es el carácter y el alcance estimado para la jurisprudencia en el derecho internacional público que, como veíamos líneas arriba, es el ascendiente del DIDH y la doctrina no lo asume de manera distinta. ${ }^{13}$

Como vemos, Méndez Silva y Gómez Robledo hacen también referencia a la cuestión sobre la jerarquía, refiriendo en la misma línea de los anteriores doctrinarios que esta no se configura como una prescripción gradacional concluyente, empero, al igual que ellos, esta posición tampoco afecta en nada el hecho de considerar a la jurisprudencia como una fuente suplementaria. Ninguno de ellos pone en duda esta aseveración, por el contrario, la reafirman. Esto, dado que el artículo 38 es claro y se ratifica en el artículo 59, al cual se remite y termina reduciendo el campo de acción de las decisiones de la Corte IDH solo a las partes. Así lo ha entendido también Becerra, quien avala el carácter subyacente de esta fuente del derecho internacional público. ${ }^{14}$

En el mismo perfil se encuentra Herdegen, aunque se muestra incluso más contundente, firmeza que se revela a partir de la delimitación y dilucidación de conceptos que, tal vez por evidentes, pueden pasar desapercibidos, mas este error no se atribuye a su indubitable fuerza específica, sino a los análisis de los investigadores y hermeneutas. Nos referimos a la carencia de subjetividad de derecho de los órganos jurisdiccionales y a la siempre mutable producción judicial incluso al interior de sus propios predios. ${ }^{15}$

consuetudinario 'obligatorio', que siempre tiene prevalencia sobre los tratados" (Matthias Herdegen, Derecho Internacional Público, México D.F., Fundación Konrad Adenauer - Universidad Nacional Autónoma de México, trad. por Marcela Anzola, 2005, p. 114).

13 Por este motivo, resulta bastante gráfico lo señalado por Méndez Silva y Gómez Robledo: “Esta disposición en su primer párrafo menciona a las convenciones internacionales, la costumbre internacional, los principios generales de derecho y las decisiones judiciales y doctrinas de los publicistas, en el caso de estas dos últimas solo como un medio auxiliar o subsidiario para la determinación de la norma jurídica. [...] Ahora bien, no podría decirse que existe dentro de la disposición enunciada, una primacía del derecho convencional sobre el derecho consuetudinario estableciéndose un orden jerárquico; esta concepción estaría contraria al principio general de interpretación, según el cual una norma especial posterior abrogaría una norma general anterior, ya se trate de derecho convencional o de derecho consuetudinario" (Méndez y Gómez, Derecho internacional público, op. cit., p. 119).

14 "El artículo 59 dice: las decisiones de la Corte no son obligatorias sino para las partes en litigio y respecto del caso que ha sido decidido. De lo expuesto podemos afirmar que las decisiones judiciales y la doctrina son solamente medios auxiliares; no son una verdadera fuente, ya que una sentencia no puede basarse solo en decisiones judiciales anteriores. Además, las decisiones de la Corte tienen la característica de relatividad: son válidas para las partes y el caso concreto que resuelven de acuerdo con el artículo 59 antes reproducido" (Manuel Becerra, Derecho internacional público, México D.F., Universidad Nacional Autónoma de México, 1991, p. 50).

15 "De acuerdo con una opinión que prevalece en la actual doctrina del derecho internacional, la Corte Internacional y otros tribunales internacionales no pueden crear ningún tipo de derecho consuetudinario, puesto que, en principio, no son sujetos del derecho internacional y sus decisiones solo vinculan a las partes que participan en la controversia. Para esta opinión, se puede también resaltar que los tribunales internacionales, de acuerdo con su propia concepción, aplican por lo general el derecho existente, pero no pueden crear nuevo derecho. A 
Para concluir, es oportuno indicar que el conocimiento y manejo de estas premisas, aunque verdaderas, no asegura el logro siempre de inferencias correctas. Mireya Castañeda nos indicaba en cita previa que "el artículo 38 es considerado como referente respecto de las fuentes del derecho internacional"; en él, como hemos visto, en su inciso d se prescribe que "las decisiones judiciales" son el "medio auxiliar para la determinación de las reglas de derecho, sin perjuicio de lo dispuesto en el artículo 59". A su vez, el artículo 59 indica que la "decisión de la Corte no es obligatoria sino para las partes en litigio y respecto del caso que ha sido decidido".

Sin embargo, líneas abajo en el mismo texto, la autora señala que

... se le ha denominado control de convencionalidad a la obligación que tienen los jueces y tribunales internos de velar por la aplicación de la Convención Americana y de su interpretación hecha por la Corte Interamericana. En esta línea, considero que surge un desdoblamiento de las fuentes del DIDH, porque su aplicación ya no solo es por un tribunal regional, sino por tribunales internos. ${ }^{16}$

La inferencia, teniendo en cuenta los precedentes, no es correcta, obviamente; sin embargo, es lamentable, como hemos podido advertir en el transcurso del presente estudio, que este equívoco parece ser una constante en el tratamiento actual de este tema.

En consecuencia, podemos darnos cuenta de que la naturaleza jurídica de la jurisprudencia en el derecho internacional y, por supuesto, aplicable también al DIDH, presenta las siguientes particularidades:

- Ostenta un carácter auxiliar, es subsidiaria.

- Es obligatoria únicamente para las partes, lo cual excluye a los ajenos al caso aun cuando fueran miembros de la $\mathrm{CADH}$.

- No existe una jerarquía definida, pero sí es claro que su gradación es baja.

- Al no ser producida por sujetos de derecho, no crea derecho consuetudinario.

- No es estable, es cambiante, por tanto, puede generar contradicción e inestabilidad jurídica.

\subsection{Y, sin embargo, ¿qué diría la filosofía del lenguaje?}

Líneas arriba hacíamos referencia a aquellas filosofías cuyo campo de acción se extiende al significado y otros conceptos del lenguaje. Dado que este trabajo

esto se añade que la misma Corte Internacional se ha separado de decisiones anteriores. De otra parte, las decisiones de los tribunales internacionales se le deben atribuir a las partes en controversia que se han sometido contractualmente a la respectiva jurisdicción" (Herdegen, Derecho Internacional Público, op. cit., p. 165).

Castañeda, El derecho internacional de los derechos humanos y su recepción nacional, op. cit., p. 42. 
trata acerca de una nueva categoría jurídica, es lógico hacer una evaluación desde los predios de la filosofía del lenguaje. Gottlob Frege, padre también de la filosofía analítica, señalaba que: "Es natural considerar entonces que a un signo (nombre, unión de palabras, signo escrito), además de lo designado, que podría llamarse la referencia del signo, va unido lo que yo quisiera denominar el sentido del signo, en el cual se halla contenido el modo de darse" ${ }^{17}$ Entonces, dado que se ha planteado el concepto de control de convencionalidad a partir de lo delineado en el concepto de control de constitucionalidad, por tanto, es necesario detenernos para realizar un ejercicio de comparación entre los dos instrumentos que dan origen a estos controles. El signo conformado por el nombre propio Constitución tiene el sentido de ser la norma fundamental jurídico-política de todo Estado soberano y se refiere, en su versión formal, al texto creado por el poder constituyente bajo un ritual solemne extraordinario. En el otro caso, el signo "convención" tiene el sentido de un pacto internacional suscrito con el fin de proteger los derechos humanos en la región americana y se refiere a un documento con forma de tratado multinacional.

El signo constitución, como vemos, viene cargado de una raíz social, es el poder constituyente $^{18}$ de un pueblo que, en ejercicio de su voluntad, decide otorgarse a sí mismo un sistema jurídico y una organización política. Por tanto, este poder es una energía anterior a todo derecho positivo, guiado por principios, valores o, lo que muchos -como el propio Sieyès-, identifican con derecho natural. ${ }^{19}$ El signo convención aludirá a un acuerdo entre Estados representados por sus poderes constituidos (poder ejecutivo y poder legislativo) ${ }^{20}$ facultados para estos efectos por la propia constitución. ${ }^{21}$ Advertimos, entonces, que en el caso del proceso constituyente vemos soberanía pura, en el caso de la convención, un origen jurídico inferior.

Por ende, no se pueden asociar ambas ideas como conceptos similares, el modo en que se presentan ambas difiere tajantemente, dado que denotan objetos distintos.

17 Gottlob Frege, Estudios sobre semántica, Barcelona, Ediciones Orbis, 1984, p. 53.

18 "Poder Constituyente. Dicha noción fue primicialmente formulada por el abate Emmanuel Sieyès en su obra ¿Qué es el tercer Estado? Consiste en la exposición primaria de la energía social de una sociedad, con el objeto de establecer una organización política y jurídica con vocación de perennidad, mediante la dación de un texto normativo fundamental denominado Constitución" (Víctor García Toma, Teoría del Estado y derecho constitucional, 3 ed., Lima, Adrus, 2010, p. 505).

19 "La nation existe avant tout, elle est l'origine de tout. Sa volonté est toujours légale, elle est la loi elle-même. Avant elle et au-dessus d'elle il n'y a que le droit natural" (Emmanuel Joseph Sieyès, Qu'est-ce que le Tiers état?, Paris, Éditions du Boucher, 2002, p. 53). ("La nación existe ante todo, es el origen de todo. Su voluntad es siempre legal, es la ley misma. Antes que ella y sobre ella solo existe el derecho natural").

20 "Tradicionalmente, se ha entendido que el derecho internacional reconoce como fuentes normativas principales los tratados o convenciones. Estos son instrumentos internacionales que, suscritos y ratificados por los estados, los obligan jurídicamente. Ejemplos de este tipo de instrumentos son el Pacto Internacional de Derechos Civiles y Políticos y la Convención Americana sobre Derechos Humanos. En ambos casos, la ratificación por parte de los estados genera para estos obligaciones ante la comunidad internacional" (Gonzalo Candia Falcón, Introducción al derecho internacional de los derechos humanos, Santiago de Chile, Ediciones Universidad Católica de Chile, 2016, p. 38).

21 En el caso del Perú, la Constitución les ha dedicado el capítulo II, artículos 55, 56 y 57. 
De otro lado, al analizar los controles de constitucionalidad y convencionalidad nos resulta que el signo conformado por el nombre propio Control de Constitucionalidad tiene el sentido de ser un conjunto de recursos orientados a garantizar la supremacía de la constitución frente a normas o actos. En cuanto a la referencia, debemos tener en cuenta lo que Frege afirma: “Quizá pueda admitirse que una expresión gramaticalmente correcta que sustituye un nombre propio tiene siempre sentido. Pero con ello no se ha dicho que al sentido le corresponda también una referencia. [...] Así pues, por el hecho de que se conciba un sentido, no se tiene con seguridad una referencia". ${ }^{22} Y$ esto, según el propio autor, es porque la referencia de un nombre propio es el objeto mismo que designamos con él, ahora bien, entonces ¿por qué buscamos una referencia? Frege es tajante, lo hacemos porque buscamos la verdad. Nos permitimos ciertas licencias dirigidas a satisfacer intereses en los que suspendemos nuestra inclinación hacia la comprobación, como es el caso del arte, pues durante su apreciación aceptamos lo que el autor nos confía, pues de lo contrario, si exigimos evidencias de ello, todo se derrumbaría y se anularía el disfrute. Esto sucede generalmente con las emociones, los sentimientos y las creencias. ${ }^{23}$

En el caso del control de constitucionalidad, al no existir un objeto sensiblemente perceptible, aplicaría lo que el autor enseguida señala: "Cuando se usan palabras de manera habitual, aquello de lo que se quiere hablar es su referencia" ${ }^{24} \mathrm{O}$ sea, en este caso, hablamos de un control dirigido a la protección de la constitución.

En esta línea, entonces, el signo control de convencionalidad tiene el sentido de ser un conjunto de recursos orientados a garantizar la exigibilidad, la obligatoriedad, el cumplimiento y la aplicación de la CADH frente a normas o actos provenientes de los funcionarios o instituciones nacionales. Cabe la pregunta de cuál sería la razón por la que protegeríamos a la $\mathrm{CADH}$, y nótese que no hemos utilizado el término "supremacía". No corresponde.

Tampoco existe un uso de palabras de manera habitual; como hemos visto, el concepto está aún en construcción, ha ido creciendo y con el tiempo se ha ido asemejando más al control de constitucionalidad, que parece tomar como modelo. En consecuencia, no podemos hablar de una referencia en el caso del signo control de convencionalidad, al menos no una propia que nos dirija a una identificación de los términos. ${ }^{25}$ En este extremo el control de convencionalidad falla.

\footnotetext{
22 Frege, Estudios sobre semántica, ob. cit., p. 54.

23 "Es la búsqueda de la verdad lo que nos incita a avanzar del sentido a la referencia. Hemos visto que a un enunciado hay que buscarle una referencia siempre que interesa la referencia de las partes componentes; y esto es siempre el caso, y solo entonces, cuando nos preguntamos por los valores veritativos. Por esto nos vemos impulsados a admitir el valor veritativo de un enunciado como su referencia. Por valor veritativo de un enunciado entiendo a circunstancia de que sea verdadero o de que sea falso. No hay más valores veritativos" (ibid., p. 62).

24 Ibid., p. 55.

25 "Lo dicho hace del control de convencionalidad un modelo todavía inacabado, en que además la doctrina desarrolla tesis diversas sobre su naturaleza, lo que da lugar a numerosas incertidumbres relativas al alcance
} 
Habiendo realizado el análisis acerca de los significados, es conveniente hacer lo propio ahora sobre la definición. Riccardo Guastini señala que es "el enunciado mediante el cual se determina el significado de un término o de una expresión compuesta (sintagma)" ${ }^{26} \mathrm{El} \mathrm{mismo} \mathrm{autor} \mathrm{afirma} \mathrm{que} \mathrm{la} \mathrm{forma}$ estándar de una definición es un enunciado, para acto seguido manifestar que esencialmente existen dos tipos de definiciones:

... (i) las definiciones informativas, las cuales describen de qué forma la expresión definida es efectivamente usada por alguien (típicos ejemplos de las definiciones lexicales o lexicográficas que se encuentran en los diccionarios de un idioma, las cuales describen de qué forma o, más a menudo, de qué formas una palabra es usada comúnmente por aquellos que hablan el idioma en cuestión);

(ii) las definiciones estipulativas, las cuales (a) proponen usar un término o sintagma preexistente de una forma nueva, (b) de una forma más precisa respecto al uso común, o (c) establecen cómo usar un término o sintagma recientemente acuñado. ${ }^{27}$

Si hacemos un recuento histórico a partir del origen del control de convencionalidad, en la sentencia del Caso Myrna Mack vs. Guatemala nos encontramos ante una definición inicial que ha pasado por recurrentes definiciones estipulativas (redefiniciones, es decir) hasta llegar a una ya detallada líneas arriba, me refiero a la que expone el cuadernillo de jurisprudencia de la Corte IDH; esta es una definición informativa en cuanto describe de qué forma la expresión definida es efectivamente usada por alguien. Esto no quita que el enunciado siga cambiando, o redefiniéndose, como parece ser su tendencia, sin embargo, tomando esta apreciación, debemos atribuirle sus características $\mathrm{y}$, en tal sentido, a decir de Guastini, "las definiciones informativas pueden ser verdaderas o falsas (según describan verídicamente, o no, el uso lingüístico efectivo)" ${ }^{28}$ Después de lo analizado en este apartado, la definición descrita acerca del control de convencionalidad solo puede ser falsa.

\section{Soberanía del Estado y supremacía constitucional frente al control de convencionalidad}

No existe Estado sin soberanía, sin importar la calificación del Estado, su forma, su régimen o sistema; se trata de una característica esencial en él (aun a despecho de aquellos que han tratado de esgrimir lo contrario ${ }^{29}$ ). Stefan Kai-

de los destinatarios, parámetro, objeto y efectos del control, que este texto buscó evidenciar" (Miriam Lorena Hernríquez Viñas, "La polisemia del control de convencionalidad interno", en International law, Revista colombiana de Derecho Internacional 24 [2014], p. 138).

26 Riccardo Guastini, Teoría analítica del derecho, Puno, Zela Grupo Editorial, 2017, p. 23.

27 Ibid., p. 24.

28 Idem.

29 Jellinek, por ejemplo, nos habla de soberanía desde una perspectiva histórica, entendiendo que muchos Estados han existido sin ella y que el carácter formal de la soberanía no alcanza para explicarla. Esto es incorrecto por parcializado, pues el concepto de soberanía ha importado un escudo para la sobrevivencia de toda construcción político-jurídica frente a terceros, que ha ido fortaleciéndose con el tiempo, es cierto, pero la idea siempre se ha sostenido, especialmente en la formación del Estado moderno. De otro lado, es discutible el fundamento respecto al concepto de Estado que usa el autor, pues extenderse con él hasta el feudalismo es cuando menos 
ser precisa atinadamente que "la soberanía de los Estados denota el derecho legal inalienable, exclusivo y supremo de ejercer poder dentro del área de su poder. El ejercicio de los poderes soberanos en la esfera nacional comprende los poderes Legislativo, Ejecutivo y Judicial, en relación con las personas físicas y morales" ${ }^{30}$ Entre muchas conclusiones a partir de este concepto podemos extraer dos: primero, la soberanía es irreductible, la segunda es que, contrario sensu, el menoscabo de la soberanía significa un daño nuclear en el Estado.

No obstante, es lógico que en la natural convivencia de los Estados se formen relaciones, en estas circunstancias también funciona la soberanía. Muchos dirían que en este caso se nota aún más, dado que se manifiesta ese carácter exclusivo y excluyente que no permite la injerencia de otros poderes. ${ }^{31}$ Los Estados, justamente en el ejercicio de su soberanía, celebran acuerdos, forman organismos, se adhieren a pactos, establecen relaciones comerciales $\mathrm{u}$ otros actos, sin embargo, nada de ello puede significar pérdida de soberanía. Así como sería absurdo que en ejercicio de la libertad se pierda libertad, sería un despropósito que en ejercicio de la soberanía se pierda soberanía. Al respecto, Kaiser refiere que "los Estados tienen la libertad de ejercer su soberanía. Pero en las relaciones exteriores de dichos Estados, ellos pueden obligarse legalmente por medio de tratados y otros acuerdos internacionales para ejercer su soberanía. A pesar de tales instrumentos internacionales, su capacidad primordial como Estado soberano no es afectada". ${ }^{32}$

Desde el constitucionalismo clásico, portador de los primeros indicios del Estado de derecho hasta el Estado constitucional de derecho hemos experimentado la traslación de la soberanía del monarca al pueblo. Martin Kriele tiene razón en afirmar que:

Para el Estado constitucional, la soberanía del pueblo significa, por tanto, que el poder constituyente y la titularidad del poder estatal los tiene el pueblo. Puesto que el concepto de soberanía del pueblo se agota en estos dos elementos, la soberanía del pueblo es perfectamente compatible con la afirmación de que no hay ningún soberano dentro del Estado constitucional. La soberanía del pueblo solo aparece al comienzo o al final del Estado constitucional, cuando este es creado y cuando este es abolido. La soberanía del pueblo puede, por consiguiente, constituir la libertad y con ello la democracia. ${ }^{33}$

arriesgado, pero esto ya sería motivo de otra investigación. Al respecto, señala: “la soberanía no ha sido nota esencial ni de los Estados de la Edad Media ni de aquellos de la época del florecimiento del dogma del Derecho Natural sobre la identidad entre Estado y poder soberano. Tampoco puede establecerse actualmente esta equivalencia, a causa de la situación real de los Estados" (Georg Jellinek, "La naturaleza de la soberanía”, en Carlos Blancas Bustamante, César Landa Arroyo y Marcial Rubio Correa [comps.], Derecho constitucional general, 4 ed., Lima, Fondo Editorial de la Pontificia Universidad Católica del Perú, 1994, tomo I, p. 216).

30 Stefan Kaiser, "El ejercicio de la soberanía de los Estados", en Manuel Becerra Ramírez y Klaus Theodor Müeller Uhlenbrock (coords.), Soberanía y juridificación en las relaciones internacionales, México, Instituto de investigaciones jurídicas de la Universidad Nacional Autónoma de México, 2010, pp. 85-105.

31 "También bajo el derecho internacional público la soberanía es inalienable. Otros Estados no pueden privar a un Estado de su soberanía. Mientras exista un Estado, este tendrá poderes soberanos" (ibid., p. 88).

32 Ibid., p. 103.

33 “...la soberanía no ha sido nota esencial ni de los Estados de la Edad Media ni de aquellos de la época del florecimiento del dogma del Derecho Natural sobre la identidad entre Estado y poder soberano. Tampoco puede 
Ahora bien, como sabemos, el poder constituyente es aquella fuerza social dirigida a la creación o reforma de la constitución a partir de la cual se origina un cuerpo político y un sistema jurídico. Siendo una potestad magna del pueblo, el producto generado por su labor comparte esta característica, esta es la lógica de la supremacía constitucional. Marcos Del Rosario lo refiere bien cuando señala que:

La Constitución posee esta condición por ser un ordenamiento soberano que califica la validez o invalidez de todas las normas. Siendo la Constitución el resultado del ejercicio soberano del poder constituyente, el cual desapareció al momento de cumplir su labor creadora, subyace como factor supremo, pues no existen poderes o normas que se le sobrepongan. ${ }^{34}$

En efecto, la condición de la supremacía constitucional, por provenir de un linaje directo investido de soberanía, da lugar a una norma magna.

Sobre el particular, Manuel Aragón Reyes señala que:

La supremacía podría ser entendida como una cualidad política de toda Constitución, en cuanto esta es siempre (al margen de cualquier consideración ideológica) un conjunto de reglas que se tienen por fundamentales, es decir, por esenciales, para la perpetuación de la forma política. La supralegalidad no es más que la garantía jurídica de la supremacía y, en tal sentido, toda Constitución (en sentido lato) tiene vocación de transformar la supremacía en supralegalidad..$^{35}$

Como vemos, soberanía estatal y supremacía de la constitución son conceptos concomitantes. No obstante, el Instituto Interamericano de Derechos Humanos (IIDH) (órgano creado en 1980 por un convenio entre la Corte IDH y la República de Costa Rica), afirma que:

En consecuencia, la exigencia de cumplimiento de las obligaciones creadas por los Estados en el Derecho Internacional no implica una transgresión a su soberanía estatal ya que, precisamente, es en ejercicio de esta que los Estados han consentido para vincularse jurídicamente con aquéllas. Y, nuevamente siguiendo la teoría de Scelle, queda en evidencia que al no existir en el ordenamiento internacional órganos centralizados y superiores a los Estados que controlen la aplicación de sus normas, estos devienen los principales responsables de la aplicación del Derecho Internacional. ${ }^{36}$

En efecto, sí se trata de una contradicción dado que es obvio que los tratados generan obligaciones, pero lo son en los extremos que se prevé en su propio texto, y es evidente también que ningún Estado suscribe tratados para contra-

establecerse actualmente esta equivalencia, a causa de la situación real de los Estados" (Kriele, "Soberanía del Pueblo", op. cit., p. 243).

34 Marcos Francisco Del Rosario Rodríguez, "La supremacía constitucional: naturaleza y alcances", en Díkaion 20, (1) (2011), p. 106.

18835 Manuel Aragón Reyes, Estudios de derecho constitucional, Madrid, Centro de Estudios Políticos y Constitucionales, 2013, p. 183.

36 Instituto Interamericano de Derechos Humanos, Manual auto-formativo para la aplicación del control de convencionalidad dirigido a operadores de justicia, San José, Instituto Interamericano de derechos humanos, 2015, p. 17. 
decir (o violar) su propio derecho interno o los principios que su constitución inscribe en su cuerpo político y sistema jurídico, más aún si estos no vulneran el convenio. Como vemos, tal presunta transgresión nace de una interpretación jurisprudencial del tratado que de ningún modo puede ser obligatoria si altera su espíritu y, por otro lado, en nombre del control de convencionalidad no se puede quebrantar la soberanía estatal al convertir en vinculante al error. Esta inconsecuencia afectaría también a la supremacía constitucional por la relación lógica con la soberanía que se ha expuesto líneas arriba. No se justifica la transgresión de la constitución, menos cuando no hay error en esta o en los dispositivos infraconstitucionales, y mucho menos a causa de un error jurisprudencial; frente a esto es legítimo oponer la calidad magna que no tienen ni el convenio, ni la Corte IDH, dado que carecen del poder conferido por la soberanía popular.

Por otro lado, en el texto mencionado, el IIDH hace referencia al artículo 38 del Estatuto de la CIJ dedicado a las fuentes del derecho internacional, el mismo que hemos analizado en un acápite anterior y que, como hemos visto, en vez de reforzar el concepto del control de convencionalidad lo debilita pues, como es lógico, reconoce la preponderancia jerárquica de las convenciones, no así de la jurisprudencia a la que considera solo un "medio auxiliar" y obligatoria solo para las partes en litigio, como lo prescribe el artículo 59.

Ahora bien, si existe el control de convencionalidad, se presume que respondería a una necesidad, la cual tendría que ser suprema para pretender reformar el concepto de soberanía. Según Claudio Nash:

... resulta importante aclarar desde un inicio que estamos ante una figura que la Corte ha tenido que desarrollar no porque esté aportando una nueva obligación a las ya existentes, sino que surge del déficit que es posible constatar en los múltiples casos que llegan al sistema de protección de derechos humanos. Esto es especialmente evidente en los casos que llegan ante la Corte IDH donde el problema se produce porque las autoridades locales, principalmente del poder judicial, no aplican las obligaciones contraídas por el Estado e incorporadas a la legislación nacional. Es decir, estamos ante una figura que viene a clarificar una obligación ya existente y la dota de contenido y especificidad. ${ }^{37}$

Lo planteado no resulta del todo acertado, como veremos. La primera afirmación es que "no se está aportando una nueva obligación a las ya existentes". Esto no es verdad. Como se ha explicado líneas arriba, esto sería cierto si el llamado al cumplimiento se circunscribiera a lo contenido en la CADH, sin embargo, la jurisprudencia se ha convertido en nuevo derecho escrito y ha alcanzado fronteras más allá del tratado, lo cual no es insignificante, este

37 Claudio Nash, "Control de convencionalidad. Precisiones conceptuales y desafíos a la luz de la jurisprudencia de la Corte Interamericana de Derechos Humanos", en Anuario de Derecho Constitucional Latinoamericano, año XIX (2013), p. 491. 
margen implica obligaciones nuevas que los Estados no habían previsto al momento de la suscripción, como ya hemos explicado. La segunda afirmación inexacta es la siguiente: "las autoridades locales, principalmente del poder judicial, no aplican las obligaciones contraídas por el Estado e incorporadas a la legislación nacional". No cuestiono el desacato, de eso conocemos de sobra los latinoamericanos, lo que quiero decir es que existe una falacia en la proposición, pues a partir de un razonamiento simple se entenderían dos cosas: o las autoridades cumplen con lo dispuesto, y en ese caso no es necesaria la intervención de la Corte IDH, o incumplen y queda expedito el camino a ella. Sin embargo, las cosas no se dan de este modo y cito un caso emblemático para ejemplificar mi afirmación, el de Artavia Murillo, en el que no solo no se contravino la $\mathrm{CADH}$, sino que, al contrario, mediante medidas internas se intentó proteger al concebido. Entonces, el razonamiento en este caso deriva en una tercera opción: las autoridades cumplen con lo dispuesto en la Convención, pero igual van a la Corte IDH y además pueden perder. ¿Cómo puede configurarse una situación tan ilógica? La razón es sencilla, es a causa del as bajo la manga de la Corte IDH, el criterio de los jueces, quienes pueden desde admitir, hasta invocar todo tipo de legislación, tratados $\mathrm{u}$ otros documentos (no pertinentes o incluso no vinculantes) $\mathrm{y}$, al final, reinterpretar la CADH para generar nuevo derecho, aun si ello significa una contraposición a su texto original, como en el caso Artavia Murillo.

Pero aún hay algo más, en la afirmación de Claudio Nash se encuentra lo siguiente: "no aplican las obligaciones contraídas por el Estado e incorporadas a la legislación nacional". La letra "e" implica conjunción, pues, como todos sabemos, la ratificación de un tratado implica su incorporación al sistema jurídico doméstico, en otras palabras, su conversión en derecho interno. Pues bien, al haberse asimilado al derecho nacional, se comprende (en el mejor de los supuestos) que no ha existido ninguna razón para considerar que es írrito. En tal sentido, por ende, existirían dos opciones: o las autoridades cumplen con la legislación interna y no resultaría necesaria la Corte IDH, o las autoridades incumplen con la legislación interna y entonces tampoco sería necesaria dicha Corte; la razón es sencilla también, porque es subsidiaria, antes se debe acudir a las vías internas. En esta línea, ¿cuándo resultaría pertinente la actuación de la Corte IDH? Pues basándonos en este último supuesto de incumplimiento de las autoridades nacionales, tenemos dos opciones: cuando se trate de un caso no previsto en la legislación interna (que ha asimilado al tratado), lo cual es improbable dado que, por principio jurídico, un juez no puede dejar de impartir justicia, ni alegar desconocimiento (volveremos a esto más adelante), lo cual nos conduce a la única opción posible: cuando se trate de un caso erróneamente resuelto en vías internas por mala aplicación de la legislación interna (que ha asimilado al tratado). En cualquiera de los dos casos, como puede apreciarse, siempre el marco referencial es la CADH. En consecuencia, en un estado ideal de cosas, no debería ser posible resolver, ni en derecho interno, ni en la Corte IDH, más allá de lo previsto en el tratado, todo lo demás 
es espurio. Más aún, si como dice el propio Claudio Nash, la intervención de la Corte IDH se daría si las autoridades "no aplican las obligaciones contraídas por el Estado", contrario sensu, más allá de lo contraído mediante el tratado no existe obligación. La sentencia Artavia Murillo no se explica.

Ahora bien, si es como dice Nash, que el control de convencionalidad no está "aportando una nueva obligación a las ya existentes", entonces resultaría en una figura inoficiosa o en todo caso redundante (y esta sería la mejor razón para suprimirla), sin embargo, este es el argumento que se esgrime para restar importancia y evitar el miedo a la introducción de un conflicto capital para el derecho contemporáneo.

Siguiendo la misma línea de Kaiser, Bidart Campos señala que la soberanía "se trata de una cualidad del poder que lo hace no dependiente ni subordinado, y que garantiza la existencia y supremacía del Estado".$^{38}$ Bajo este enunciado, el Control de Convencionalidad queda vetado pues exige la adecuación de las estructuras estatales. No obstante, otras versiones del concepto son más flexibles como lo documenta el maestro Peter Häberle cuando señala que:

En la medida en que, desde la perspectiva internacional, la cooperación entre los Estados ocupe el lugar de la mera coordinación y del simple ordenamiento de la coexistencia pacífica (es decir, de la delimitación de los ámbitos de la soberanía nacional), en el campo del derecho constitucional nacional pueden advertirse tendencias que apuntan hacia un debilitamiento de la distinción estricta entre lo interno y lo externo a favor de una apertura hacia el exterior. ${ }^{39}$

Luego, en relación con los cambios en varias normas fundamentales alrededor del mundo afirma que "los nuevos artículos constitucionales, al permitir la transmisión de poderes soberanos a organizaciones e instituciones supraestatales o internacionales, documentan una disposición a renunciar a la soberanía que era ajena al derecho internacional tradicional". ${ }^{40}$

Pues bien, en lo referido a las relaciones entre el Estado y la interpretación de tratados, la soberanía se traduce en la figura del margen de apreciación, sin embargo, quienes rechazan a la soberanía en su acepción fuerte, por ende lo terminan haciendo también con su consecuente, por ello Eirik Bjorge afirma que "public international law would, however, from the end of the Second World War and onwards, undergo substantial change in respect of issues of sovereignty and the view of how acceptable doctrines of margins of appreciation really were in the intercourse of states". ${ }^{41}$ Para más adelante concluir que:

García Toma, Teoría del Estado y derecho constitucional, op. cit., p. 102.

39 Peter Häberle, El Estado constitucional, México D.F. - Lima, Universidad Nacional Autónoma de México - Pontificia Universidad Católica del Perú, 2003, p. 73.

$40 \quad$ Ibid., p. 74

41 Eirik Bjorge, "Been there, done that: the margin of appreciation and international law", en Cambridge Journal of International and Comparative Law 4 (issue 1) (2015), p. 187. “Sin embargo, el derecho internacional público, 
... To international law, the margin of appreciation is decidedly old hat. International law, having originated the doctrine, jettisoned it in the early postwar years. Those who think they have something to teach international law by arguing that it adopt the by now fairly hackneyed doctrine of the margin of appreciation are late by approximately 60 years. ${ }^{42}$

Renglones arriba advertíamos acerca de la improbabilidad de la existencia de un caso no previsto por la legislación interna, entendida esta como la suma del derecho doméstico y el producido por tratados que han sido incorporados en el sistema nacional. Pues bien, la improbabilidad es cierta, pero pongámonos en el supuesto de que las autoridades no hayan dejado de aplicar el derecho, incluso si es un caso no previsto ni en el derecho nacional ni en el internacional, en ambos no existe derecho escrito, ni pronunciamiento jurisprudencial, se agotan las vías internas y se invoca a la Corte IDH. Este sí es un caso posible. ¿Qué debe hacer la Corte IDH? ¿Crear nuevo derecho a partir de la interpretación? Según nuestra posición, esto no solamente no es siempre necesario, sino que puede ser contraproducente. Si la autoridad estatal resuelve la alteridad sin contravenir ningún extremo de la CADH, no debería ser la Corte IDH la que resuelva, sino dejar esta labor en manos del derecho interno. En similares términos se pronuncia Gonzalo Candia cuando afirma que

... el margen de apreciación es un criterio de análisis judicial que aconseja al juez internacional deferir en favor de la posición del estado en aquellos casos en que las autoridades nacionales se encuentren mejor posicionadas para resolver los mismos, debido a: (a) su mayor legitimidad democrática, (b) la existencia de una práctica común dentro del sistema regional en cuestión o (c) el expertise institucional de la autoridad nacional. ${ }^{43}$

Ahora bien, la pregunta es evidente, ¿se configura la Corte IDH como una mejor opción que los tribunales nacionales para resolver sus casos más conflictivos? Alexandra Huneeus ensaya una respuesta:

Scholars have portrayed the Inter-American Court as unmoored from the political reality of the region. Gerald Neuman argues that the jurisprudence of the Court does not adequately reflect state practice or a regional consensus. Stephanie Brewer and James Cavallaro contend that the Court has been out of touch with local political dynamics, and should focus on working with social movements in the different nations of the region. ${ }^{4}$

desde el final de la Segunda Guerra Mundial y en adelante, sufriría cambios sustanciales con respecto a las cuestiones de soberanía y la visión de cuán aceptables eran realmente las doctrinas de los márgenes de apreciación en la relación entre estados" (traducción propia).

42 Ibid., p. 190. "Para el derecho internacional, el margen de apreciación se encuentra absolutamente en el pasado. El derecho internacional, que originó tal doctrina, se deshizo de ella en los primeros años de posguerra. Aquellos que piensan que tienen algo que enseñar en derecho internacional argumentando que se inclina por la doctrina bastante limitada del margen de apreciación llegan tarde por aproximadamente 60 años" (traduc-

$19243 \quad \begin{aligned} & \text { ción propia). } \\ & \text { Candia Falcón, Introducción al derecho internacional de los derechos humanos, op. cit., p. } 64 .\end{aligned}$

44 Alexandra Huneeus, "Courts resisting Courts: Lessons from the Inter-American Court's struggle to enforce Human Rights”, en Cornell International Law Journal 44 (issue 3), article 2 (2011), p. 531. “Los académicos describen a 
Como vemos, el cuestionamiento sobre la actuación de la Corte IDH estriba, entre otras cosas que ya se han expuesto, en el debilitamiento injustificado de la soberanía mediante el uso del control de convencionalidad, lo que afecta también a la supremacía constitucional y con ello todo el andamiaje del sistema jurídico y el cuerpo político de una nación; de otro lado, como hemos visto, en muchos casos no resulta necesaria la actuación de la Corte IDH y, por el contrario, lo más recomendable sería atender al contacto directo ya existente entre las autoridades locales y su sociedad, del cual carece el ente interamericano. Lo que debería buscarse en todo caso, y esto no es ningún descubrimiento, es fortalecer las instituciones internas para resolver los casos con las herramientas que ya se posee y recurrir a la Corte IDH, cuidando que sus pronunciamientos no vulneren sus propios límites. La naturaleza magna de la constitución -de la cual carece la CADH- es, junto a sus principios, muchas veces remedio más que suficiente para las alteridades internas. La primera labor de las instituciones alrededor de la CADH debería ser robustecer estos extremos, después de todo, las finalidades son las mismas. Desde la otra orilla, el margen de apreciación no solo no ha perdido vigencia, sino que puede representar el último reducto por el que la soberanía puede ser preservada y con ella el sistema jurídico y el cuerpo político.

\section{Mientras tanto en el Perú}

La cuarta disposición final y transitoria de la Constitución de 1993 prescribe lo siguiente: “Las normas relativas a los derechos y a las libertades que la Constitución reconoce se interpretan de conformidad con la Declaración Universal de Derechos Humanos y con los tratados y acuerdos internacionales sobre las mismas materias ratificados por el Perú".

Esta es la norma que recurrentemente invocan quienes defienden el control de convencionalidad, pues a partir de una rápida interpretación resulta aparentemente que en temas de derechos y libertades constitucionales todo significado debe adecuarse a los tratados, sin embargo, en realidad pueden darse tres escenarios interpretativos distintos:

Los derechos y las libertades constitucionales, al interpretarse a la luz de los tratados son compatibles con la Constitución. En este caso, con aplicar la Constitución hubiese sido suficiente, ya que el resultado es el mismo.

Los derechos y las libertades constitucionales, al interpretarse a la luz de los tratados resultan complementando, desarrollando, potenciando o agregando

la Corte Interamericana como alejada de la realidad política de la región. Gerald Neuman argumenta que la jurisprudencia de la Corte no refleja adecuadamente la práctica estatal o un consenso regional. Stephanie Brewer y James Cavallaro sostienen que la Corte no tiene contacto con la dinámica política local y debería enfocarse en trabajar con los movimientos sociales en las diferentes naciones de la región" (traducción propia). 
a lo previsto en la Constitución. En este caso, las disposiciones normativas del tratado enriquecen el bloque de constitucionalidad y a la constitución misma en favor de los principios expuestos en ella y principalmente de las personas. Este es un escenario auspicioso.

Los derechos y las libertades constitucionales, al interpretarse a la luz de los tratados, resultan en una interpretación incompatible con la constitución. Entonces, cabe la pregunta, ¿debe aplicarse la interpretación de un presunto derecho o libertad constitucional contraria a la constitución? $\mathrm{O}$, más grave aún, ¿se debe aplicar una interpretación inconstitucional o anticonstitucional?

Para muestra el fundamento 222 del caso Artavia Murillo ya referido. En la sentencia la Corte IDH, al interpretar a la CADH señala que "no es factible sostener que un embrión sea titular y ejerza los derechos consagrados en cada uno de dichos artículos. [...] el objeto directo de protección es fundamentalmente la mujer embarazada, dado que la defensa del no nacido se realiza esencialmente a través de la protección de la mujer". Si tenemos en cuenta lo revisado en la presente investigación, recordemos lo que la Corte IDH entiende por control de convencionalidad. En la sentencia del Caso Rosendo Cantú y otra vs. México, ya revisada, se señala que "el Poder Judicial debe tener en cuenta no solamente el tratado, sino también la interpretación que del mismo ha hecho la Corte Interamericana, intérprete última de la Convención Americana" (en otras sentencias como Almonacid Arellano, Myrna Mack, Radilla Pacheco o Cabrera García y Montiel Flores se señala exactamente lo mismo). En tal sentido, siguiendo la línea de este razonamiento, el fundamento 222 que acabamos de revisar debería ser acatado por los jueces de los países parte de la $\mathrm{CADH}$; ahora bien, esto no sería problema si no fuese porque en países como el Perú, una prescripción en tal sentido, aparte de ser inválida en sí misma, es también abiertamente inconstitucional.

La Constitución Política del Perú señala:

Artículo $1^{\circ}$. La defensa de la persona humana y el respeto de su dignidad son el fin supremo de la sociedad y del Estado.

Artículo $2^{\circ}$. Toda persona tiene derecho:

1. A la vida, a su identidad, a su integridad moral, psíquica y física y a su libre desarrollo y bienestar. El concebido es sujeto de derecho en todo cuanto le favorece.

Una vez más, es pertinente la pregunta: ¿están obligados los jueces a aplicar una interpretación inconstitucional o anticonstitucional? Por supuesto que no, por ello, la cuarta disposición final y transitoria no puede ser entendida a rajatabla como la adecuación del derecho nacional con respecto a lo dispuesto por la CADH. 
Y, sin embargo, si tomamos en cuenta todo lo revisado hasta aquí, resultaría que la adopción de una posición de este tipo sería a la larga, con respecto a la Corte IDH, contraproducente, pues de optarse por la inobservancia de lo interpretado por ella, lo único que se lograría es postergar en el tiempo una circunstancia a todas luces inexorable, dado que una vez agotadas las vías nacionales, en instancias de la Corte IDH sería suficiente para ella con citarse a sí misma para fundamentar su posición y zanjar esa pretendida discrepancia; es decir que, si un juez nacional deseara evitar este escenario desfavorable debería ajustarse a lo planteado por la Corte IDH cuando el proceso aún esté en sus fueros.

De otro lado, debe apreciarse que, si la interpretación de la Corte IDH es tan obligatoria como la CADH misma, sus decisiones tienen el mismo carácter de ley escrita. Ya ni siquiera hablamos de un legislador negativo al estilo de un tribunal constitucional, dado que tiene el poder de dar prescripciones normativas en las sentencias y realiza, a falta de un órgano regular encargado para ello, un rol legislativo, además del judicial propio de su naturaleza.

Por tanto, al hablar de la obligatoriedad de observancia de lo interpretado por la Corte IDH, no se está confundiendo derecho positivo con jurisprudencia, la interpretación de la Corte es vinculante y dice lo que la CADH es, consecuentemente, para todos los efectos: norma escrita.

Ante este contexto veamos qué perspectivas pueden presentarse. Revisemos los artículos 46 y 146, inciso 1, de la Constitución peruana: "Artículo $46^{\circ}$. Nadie debe obediencia a un gobierno usurpador, ni a quienes asumen funciones públicas en violación de la Constitución y de las leyes. La población civil tiene el derecho de insurgencia en defensa del orden constitucional. Son nulos los actos de quienes usurpan funciones públicas".

Si un juez en ejercicio decide aplicar una interpretación manifiestamente inconstitucional, como la del caso Artavia Murillo que hemos reseñado, ¿estamos obligados a obedecer?

"Artículo $146^{\circ}$. [...] El Estado garantiza a los magistrados judiciales: 1. Su independencia. Solo están sometidos a la Constitución y la ley".

Si una garantía de los jueces es su independencia y, al mismo tiempo, se les asegura que su única sumisión es a la constitución y a la ley, ¿puede sometérseles en virtud de una convención al cumplimiento de una disposición inconstitucional? De proceder de esta manera, ¿un juez estaría quebrantando su único sometimiento constitucional? ¿Sería prevaricador?

Ambos numerales de la Constitución peruana nos remiten primero a pensar 195 en el orden jerárquico que describen: primero Constitución y luego ley. Por 
tanto, es inconstitucional un mandato que ordena a los jueces nacionales resolver de una u otra forma, además, dado que los tratados son inferiores a la Constitución o, en todo caso, del mismo nivel si su materia es derechos humanos, no pueden vulnerarla; si son inferiores no tienen el poder de hacerlo y si son cojerárquicos tienen un deber de armonía; en cualquier caso, no pueden incordiar a la carta política.

Toda interpretación contraria al espíritu de la Constitución o incluso al tratado mismo se reviste de falso derecho y no es obligatoria. Los magistrados y todo aquel que cumpla funciones públicas se debe a la Constitución, a los tratados que no la contravengan y a la ley, las interpretaciones que violen esta concepción son inaceptables.

Por otro lado, pueden notarse dos cosas, la primera es que la actividad de la Corte IDH en ejercicio del control de convencionalidad no es un acto receptivo de adecuación, sino activo, genera nuevo derecho; la segunda es que, con respecto al derecho interno, puede devenir en su contradictorio. Por ello llaman la atención sentencias como la del caso Tarazona Arrieta y otros vs. Perú, pues se alude a un presunto carácter complementario del SIDH con respecto al derecho interno ${ }^{45}$ esto es inexacto. Entiéndase por complemento: cosa, cualidad o circunstancia que se añade a otra para hacerla íntegra o perfecta. ${ }^{46} \mathrm{El}$ sistema interamericano de protección de los derechos humanos (SIDH) y la Corte IDH no cumplen esta función con respecto al Derecho interno.

Finalmente, no cuestionamos el inestimable valor que tiene la CADH, también denominada Pacto de San José, ni las labores que cumplen los órganos creados a partir de su existencia, en especial las que ha cumplido y cumple la Corte IDH; la importancia de este sistema regional es indubitable, en especial tomando en cuenta la historia y el escenario del continente, donde los sistemas nacionales fracasaron tantas veces o conjuraron en contra de su deber de protección de estos derechos. Las críticas se extienden a lo explícitamente señalado en la presente investigación.

\section{Conclusiones}

5.1 No se puede hacer un símil entre los tribunales constitucionales y la Corte IDH o entre la constitución y la $\mathrm{CADH}$, sus naturalezas jurídicas son absolu-

$45 \quad$ Fundamento 137. "Por tanto, la responsabilidad estatal bajo la Convención solo puede ser exigida a nivel internacional después de que el Estado haya tenido la oportunidad de establecer, en su caso, una violación de un derecho y reparar el daño ocasionado por sus propios medios. Lo anterior se asienta en el principio de complementariedad (o subsidiariedad), que informa transversalmente el Sistema Interamericano de Derechos Humanos, el cual es, tal como lo expresa el Preámbulo de la misma Convención Americana, 'coadyuvante o complementario de la [protección] que ofrece el derecho interno de los Estados americanos"'.

46 Real Academia Española, Diccionario de la lengua española, Primera acepción de "Complemento", Madrid, Espasa, 2014. 
tamente diferentes, hacerlo entraña un error lógico y jurídico fatal. La constitución nace de la voluntad popular expresada en el poder constituyente. Este le da legitimidad, valor, supremacía, se trata de la propia voluntad popular que actúa y se otorga a sí misma un orden máximo. No existe un poder social superior. La CADH nace de un acuerdo interestatal, donde los poderes ya están constituidos, por tanto, asumir que esta pueda someter o conducir a la Constitución implica que se erija sobre el poder constituyente y eso, por lo ya expuesto, es imposible, se trata de un orden jurídico inferior.

5.2 El análisis a partir de la filosofia del lenguaje nos permite conocer que convención y constitución no son equiparables, de la misma forma en que no lo son control de convencionalidad y control de constitucionalidad, sus significados son distintos y, por tanto, además de forzada, resulta errónea la idea de tomar elementos de uno y asimilarlos en otro.

5.3 Cuando se trata de justificar la actuación de la Corte IDH y su proceder respecto de las constituciones, los poderes de los Estados o su derecho nacional, se recurre a una premisa que reza: "si el acuerdo ha sido aceptado por los Estados partes en ejercicio de su soberanía, estos deben cumplirlo". Es cierto en parte, pues en el caso que esto signifique inconstitucionalidad, irracionalidad, incoherencia, pérdida de soberanía u otros, no puede aceptarse. No se puede, en ejercicio de la soberanía, entregar la soberanía. Así como no se puede, en ejercicio de la democracia destruir a la democracia. Lo antidemocrático debe ser perseguido y expulsado, lo antisoberánico, también.

5.4 Si a partir de estas posiciones críticas se piensa que puede dejarse indefenso al individuo, esto no es cierto. Si frente a una circunstancia aparentemente vulneradora de los derechos humanos se tiene un dispositivo constitucional que la neutralice, y es absolutamente claro en ello, no hay razón para invocar a la $\mathrm{CADH}$, y si esta es invocada y su aplicación o la interpretación que de ella hace la Corte IDH deviene en inconstitucional, no debe ser aplicada. No es lógico, ni jurídicamente legítimo invocar la $\mathrm{CADH}$ a despecho de la constitución o en contra de ella. Si puede recurrirse a la constitución y sus preceptos son claros, es deber de todo ciudadano recurrir a ella, incluidos los jueces de manera preferente en esta premisa.

5.5 Ante la corriente que argumenta a favor del ascenso de la $\mathrm{CADH}$ indicando que la constitución es vulnerada o incumplida recurrentemente y, por tanto, es necesario un mandato jurídico externo, debemos señalar que este es un fundamento insostenible y constituye una indigencia lógica, dado que estariamos intentado solucionar un problema interno con un elemento exógeno, cuando lo sencillo y evidente sería solo recurrir al poder mandatorio de la propia constitución y revestirlo de la especial jerarquia y preponderancia que legitima e intrinsecamente le corresponden, categoría irrefutable que se encuentra al alcance de la mano.

5.6 El derecho es móvil, sin embargo, se precia de que uno de sus valores más importantes sea la seguridad jurídica, esto a fin de evitar la impredictibilidad y lograr que las personas lo sientan como un soporte y no como un riesgo o una eventualidad. El derecho es cambiante, las interpretaciones también. 
De hecho, estas influyen notablemente en este carácter, por ende, si una norma de la $\mathrm{CADH}$ es interpretada por la Corte IDH en un sentido, no es obligatorio que deba observarse esta manera de interpretar, especialmente si se vulneran principios constitucionales o sociales. De otro lado, sin perjuicio de lo señalado, no puede conminarse a un juez, representante de un poder del Estado, a interpretar de una forma u otra. Puede sugerírsele, pero de ninguna manera esta premisa puede tener carácter obligatorio. Vulnera la calidad e investidura de su cargo.

5.7 La CADH exige cumplimiento, la presente investigación no lo niega, al contrario, lo fomenta, pero esto no se aplica necesariamente a la jurisprudencia de la Corte IDH cuyos cambios incluso modifican el sentido del texto del tratado. Por ello es pertinente el margen de apreciación, concepto que se mantiene vigente y preserva la soberanía del Estado y sus sistemas jurídico y político, dado que el control de convencionalidad debilita tal concepto y, además, genera nuevas obligaciones. Sin embargo, no todas ellas son vinculantes, especialmente si afectan a la constitución; debe entenderse, entonces, que la Corte IDH no tiene necesidad de crear nuevo derecho y, en muchos casos, aceptar que el derecho interno está mejor posicionado para resolver algunas alteridades. Es preciso fortalecer la supremacía constitucional.

\section{Bibliografía}

Aragón Reyes, Manuel, Estudios de derecho constitucional, Madrid, Centro de Estudios Políticos y Constitucionales, 2013.

Atienza, Manuel, "Para una ontología de la norma jurídica", en El Basilisco 3 (julio-agosto, 1978), en https:/dialnet.unirioja.es/descarga/articulo/2979197.pdf

Becerra, Manuel, Derecho internacional público, México D.F., Universidad Nacional Autónoma de México, 1991.

Bjorge, Eirik, "Been There, Done That: The Margin of Appreciation and International Law", en Cambridge Journal of International and Comparative Law 4 (1) (2015). DOI: https://doi.org/10.7574/cjicl.04.01.181

Borea Odría, Alberto, Los elementos del Estado moderno, Lima, Centro de Estudios legislativos, económicos y sociales, 1994.

Carbonell, Miguel, "Introducción general al control de convencionalidad”, en Luis González y Diego Valadés (coords.), El constitucionalismo contemporáneo, México D.F., Fondo Editorial de la Universidad Nacional Autónoma de México, 2013.

Candia Falcón, Gonzalo, Introducción al derecho internacional de los derechos humanos, Santiago de Chile, Pontificia Universidad Católica de Chile, 2016. 
Castañeda, Mireya, El derecho internacional de los derechos humanos y su recepción nacional, México D.F., Comisión Nacional de los Derechos Humanos, 2012.

Del Rosario Rodríguez, Marcos Francisco, “La supremacía constitucional: naturaleza y alcances", en Díkaion 20 (1) (2011).

Del Toro Huerta, Mauricio Iván, “El principio de subsidiariedad en el derecho internacional de los derechos humanos con especial referencia al sistema interamericano", en Manuel Becerra Ramírez (coord.), La Corte Interamericana de Derechos Humanos a veinticinco años de su funcionamiento, México D.F., Instituto de investigaciones jurídicas de la Universidad Nacional Autónoma de México, 2007.

Dulitzky, Ariel, "An Inter-American Constitutional Court? The Invention of the Conventionality Control by the Inter-American Court of Human Rights", en Texas International Law Journal 50 (issue 1) (2015), en http://www.corteidh.or.cr/tablas/r33557.pdf

Gottlob Frege, Estudios sobre semántica, Barcelona, Ediciones Orbis, 1984.

García Toma, Víctor, Teoría del Estado y derecho constitucional, 3 ed., Lima, ADRUS, 2010.

Häberle, Peter, El Estado constitucional, México D.F. - Lima, Universidad Nacional Autónoma de México - Pontificia Universidad Católica del Perú, 2003.

Hernríquez Viñas, Miriam Lorena, “La polisemia del control de convencionalidad interno", en International law, Revista colombiana de Derecho Internacional 24 (2014). DOI: https://doi.org/10.11144/Javeriana.IL14-24.pcci

Herdegen, Matthias, Derecho internacional público, México D.F., Fundación Konrad Adenauer - Universidad Nacional Autónoma de México, traducido por Marcela Anzola, 2005.

Huneeus, Alexandra, "Courts resisting Courts: Lessons from the Inter-American Court's struggle to enforce Human Rights", en Cornell International Law Journal 44 (issue 3, article 2) (2011), en https://scholarship.law.cornell. edu/cilj/vol44/iss3/2/

Instituto Interamericano de Derechos Humanos, Manual autoformativo para la aplicación del control de convencionalidad dirigido a operadores de justicia, San José, Instituto Interamericano de Derechos Humanos, 2015.

Jellinek, Georg, “La naturaleza de la soberanía”, en Carlos Blancas Bustamante, César Landa Arroyo y Marcial Rubio Correa (comp.), Derecho constitucional general, 4 ed., Lima, Fondo Editorial de la Pontificia Universidad Católica del Perú, tomo I, 1994 . 
Kaiser, Stefan, "El ejercicio de la soberanía de los Estados", en Manuel Becerra Ramírez y Klaus Theodor Müeller Uhlenbrock (coords.), Soberanía y juridificación en las relaciones internacionales, México, Instituto de investigaciones jurídicas de la Universidad Nacional Autónoma de México, 2010.

Kriele, Martin, "Soberanía del pueblo", en Carlos Blancas Bustamante, César Landa Arroyo y Marcial Rubio Correa (comps.), Derecho constitucional general, 4 ed., Lima, Fondo Editorial de la Pontificia Universidad Católica del Perú, tomo I, 1994.

Méndez Silva, Ricardo y Gómez Robledo, Alonso, Derecho internacional público, México D.F., Universidad Nacional Autónoma de México, 1981.

Mosquera Monelos, Susana, "Reflexiones sobre la interpretación de la convencionalidad de los derechos humanos en un caso de justicia transicional", en Pedro Grández Castro (coord.), Cuadernos sobre jurisprudencia constitucional, Lima, Palestra editores, diciembre, 2016, núm. 11.

Nash, Claudio, "Control de convencionalidad. Precisiones conceptuales y desafíos a la luz de la jurisprudencia de la Corte Interamericana de Derechos Humanos", en Anuario de Derecho Constitucional Latinoamericano, año XIX (2013), en https://revistas-colaboracion.juridicas.unam.mx/index.php/ anuario-derecho-constitucional/article/view/4049

Radbruch, Gustav, Introducción a la filosofía del derecho, México D.F., Fondo de Cultura Económica, 2005.

Sieyès, Emmanuel Joseph, Qu'est-ce que le Tiers état ?, Paris, Éditions du Boucher, 2002.

Silva Abbot, Max, "Control de convencionalidad interno y jueces locales: un planteamiento defectuoso", en Estudios constitucionales 14 (2) (2016). DOI: https://doi.org/10.4067/S0718-52002016000200004

Sobrevilla, David, Historia de la filosofía del derecho, Lima, Editorial Universitaria de la Universidad Ricardo Palma, tomo I, 2012.

Welzel, Hans, Introducción a la filosofía del derecho, 2 ed., Madrid, Aguilar, 1979.

\section{Jurisprudencia Corte IDH (en orden cronológico)}

Caso Myrna Mack vs. Guatemala, Sentencia de 25 de noviembre de 2003.

Caso Tibi vs. Ecuador, Sentencia de 07 de setiembre de 2004.

200 Caso Almonacid Arellano y otros vs. Chile, Sentencia de 26 de setiembre de 2006.

Caso Aguado Alfaro y otros vs. Perú, Sentencia de 24 de noviembre de 2006. 
Caso Heliodoro Portugal vs. Panamá, Sentencia de 12 de agosto de 2008.

Caso Radilla Pacheco vs. México, Sentencia de 23 de noviembre de 2009.

Caso Fernández Ortega y otros vs. México, Sentencia de 30 de agosto de 2010.

Caso Rosendo Cantú y otra vs. México, Sentencia de 31 de agosto de 2010.

Caso Cabrera García y Montiel Flores vs. México, Sentencia de 26 de noviembre de 2010.

Caso Atala Riffo y niñas vs. Chile, Sentencia de 24 de febrero de 2012.

Caso Gelman vs. Uruguay, Sentencia de 24 de febrero de 2011.

Caso Artavia Murillo vs. Costa Rica, Sentencia de 28 de noviembre de 2012.

Caso Tarazona Arrieta vs. Perú, Sentencia de 15 de octubre de 2014.

\section{Legislación}

Constitución Política del Perú de 1993.

Convención Americana sobre Derechos Humanos (Pacto de San José de Costa Rica).

Convención de Viena sobre Derecho de los Tratados.

Estatuto de la Corte Internacional de Justicia (contenido en la Carta de las Naciones Unidas).

Cuadernillo núm. 7 de Jurisprudencia de la Corte Interamericana de Derechos Humanos. 